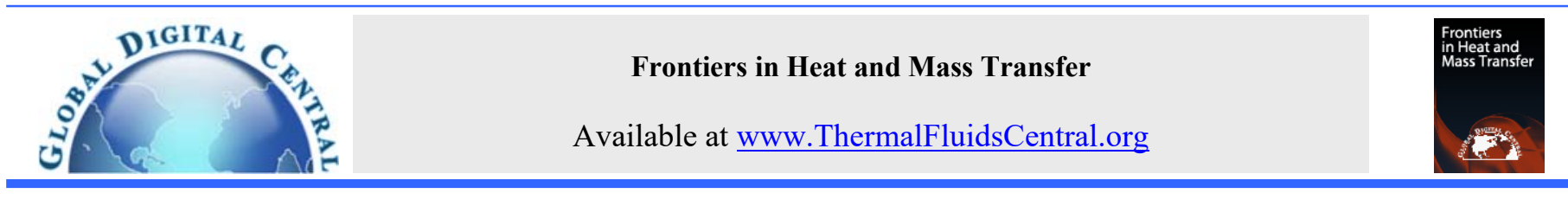

\title{
THERMAL PERFORMANCE ASSESSMENT IN A CIRCULAR TUBE FITTED WITH VARIOUS SIZES OF MODIFIED V-BAFFLES: A NUMERICAL INVESTIGATION
}

\author{
Amnart Boonloi ${ }^{\mathrm{a}}$ and Withada Jedsadaratanachai ${ }^{\mathrm{b},}$ \\ ${ }^{a}$ Department of Mechanical Engineering Technology, College of Industrial Technology, King Mongkut’s University of Technology North Bangkok, \\ Bangkok 10800, Thailand \\ ${ }^{b}$ Department of Mechanical Engineering, School of Engineering, King Mongkut's Institute of Technology Ladkrabang, Bangkok 10520, Thailand
}

\begin{abstract}
This research reports numerical examinations on fluid flow, heat transfer behavior and thermal performance analysis in a circular tube equipped with modified V-baffles (CTMVB). The modified V-baffle (MVB) is a combination vortex generator between V-baffles/V-orifices which are placed on the tube wall and V-baffles which are inserted at the core of the tested tube. The MVB height is separated into two parts; b1 represents the MVB height on the tube wall, while $\mathrm{b}_{2}$ represents the MVB height at the core of the tested round tube. The MVB height to tube diameter ratios, $\mathrm{b} / \mathrm{D}$, are adjusted; $b_{1} / D=0.05,0.1,0.15$ and 0.2 , and $b_{2} / D=0.025,0.05,0.075$ and 0.1 . The Reynolds numbers of about $100-2000$ (laminar regime) are considered. The flow directions in the tested section; V-tip directing downstream and V-tip directing upstream, are discussed. The flow attack angles for the MVB, $\alpha$, of about $20^{\circ}$ and $30^{\circ}$ are compared. The finite volume method with SIMPLE algorithm (a commercial code) is opted to analyze the present investigation. The computational domain of the CTMVB is validated (grid independence and smooth tube validations). It is found that the MVB generates many vortex cores in the tested section. The vortex flows near the tube wall disrupt thermal boundary layer, while the vortex flows at the center of the tube help superior fluid blending. The disturbed thermal boundary layer and the better fluid blending are main two causes for heat transfer augmentation. In addition, the best thermal enhancement factor of the CTMVB is found to be around 3.92.
\end{abstract}

Keywords: modified V-baffle; heat exchanger; circular tube; vortex generator; thermal performance.

\section{INTRODUCTION}

There are many teams of researchers who have been trying to improve ability of heat transfer for various heat exchangers such as fin-and-tube heat exchangers (Jinlong and Hsiao Mun (2020), Modi et al. (2020) and Gupta et al. (2020)), shell-and-tube heat exchangers (Yu et al. (2020), Chamoli et al. (2018a), Liu et al. (2018), Piriyarungrod et al. (2018), Eiamsa-ard et al. (2019)), plate-fin heat exchangers (Samadifar and Toghraie (2018) and Khoshvaght-Aliabadi et al. (2016)), solar air heaters (Chamoli et al. (2018b). The researchers have been selecting two modes; active and passive methods, to improve thermal efficiency and heat transfer coefficient in the heating/cooling systems. The active method is an addition of external power into the systems to enhance the heat transfer coefficient. An installation of vortex generators or turbulators into the heating/cooling sections to generate vortex flows which disturb thermal boundary layer is called "the passive method". The thermal improvement of the heat exchangers with the active method may affect for investment cost of production processes, while the passive technique can remain the operating cost similarly as general processes.

The investigations on heat transfer and flow field can be done by both experimental and numerical studies. The experimental results from validated device have high accuracy, while the numerical results (Abotsi and Kizito (2020), Gao et al. (2020), Gu et al. (2020), Li et al. (2020) and Hiratsuka et al. (2020)) can help to describe the flow and heat transfer mechanisms.

The experimental and numerical results; heat transfer patterns, flow fields and performance assessments, for the installation of the

*Corresponding author. Email: withada.je@kmitl.ac.th vortex generators have been illustrated by many researchers. For some cases, Bahiraei et al. (2020) examined the heat transfer enhancement in a square section equipped with V-shaped ribs combining with nanofluid. The $45^{\circ} \mathrm{V}$-shaped rib was compared with the $60^{\circ} \mathrm{V}$-shaped rib. The results revealed that the $45^{\circ} \mathrm{V}$-shaped rib gives lower entropy generation than the $60^{\circ} \mathrm{V}$-shaped rib. They summarized that the bigger rib height with smaller pitch spacing provides lower exergy destruction and augments higher second law efficiency. Bahiraei et al. (2019) numerically studied the thermohydraulic performance of $\mathrm{Cu}$-water nanofluid in a square duct placed with $90^{\circ} \mathrm{V}$-shaped ribs. The rib parameters: rib height and rib pitch, were considered. They reported that the Nusselt number enhances about $28.3 \%$ when increasing the rib height from 2.5 to $7.5 \mathrm{~mm}$ at the pitch spacing of $50 \mathrm{~mm}$. Matsubara $e t$ al. (2020) presented the direct simulation of the entry effect for a channel placed with ribs at Reynolds number of 20,460. They claimed that the disturbed thermal boundary affects for the heat transfer enhancement at the entry regime of the ribbed channel. Li et al. (2020) studied the heat transfer and flow characteristics in a microchannel with solid and porous ribs. They found that the thermal performance in the ribbed microchannel is greater than the general reference without rib. Bahiraei et al. (2020) presented the second law analysis in a channel placed with conical ribs. The influences of rib arrangements and nanoparticle shapes on flow configurations and heat transfer profiles were measured. Jiang et al. (2020) investigated the fluid flow and heat transfer mechanisms of two-phase flow in a rectangular section installed with column-row-rib. Bai et al. (2019) studied the rib disturbed entrance effect in a pin-fin array for $\mathrm{Re}=7000-40,000$. The three rib configurations; $60^{\circ}$ rib, $\mathrm{V}$-shaped rib and $\mathrm{W}$-shaped rib, were compared. The results revealed that the entrance effect not only increases the heat transfer rate, but also decreases the pressure drop. $\mathrm{Li}$ et al. (2019) evaluated the pressure loss, heat transfer and efficiency in 
a channel equipped with miniature structured ribs on one wall for turbulent flow $(\operatorname{Re}=10,000-60,000)$ by both numerical and experimental studies. Their results showed that the averaged Nusselt number and overall Nusselt number are greater than the smooth channel around $2.2-2.6$ and $2.9-3.3$ times, respectively.
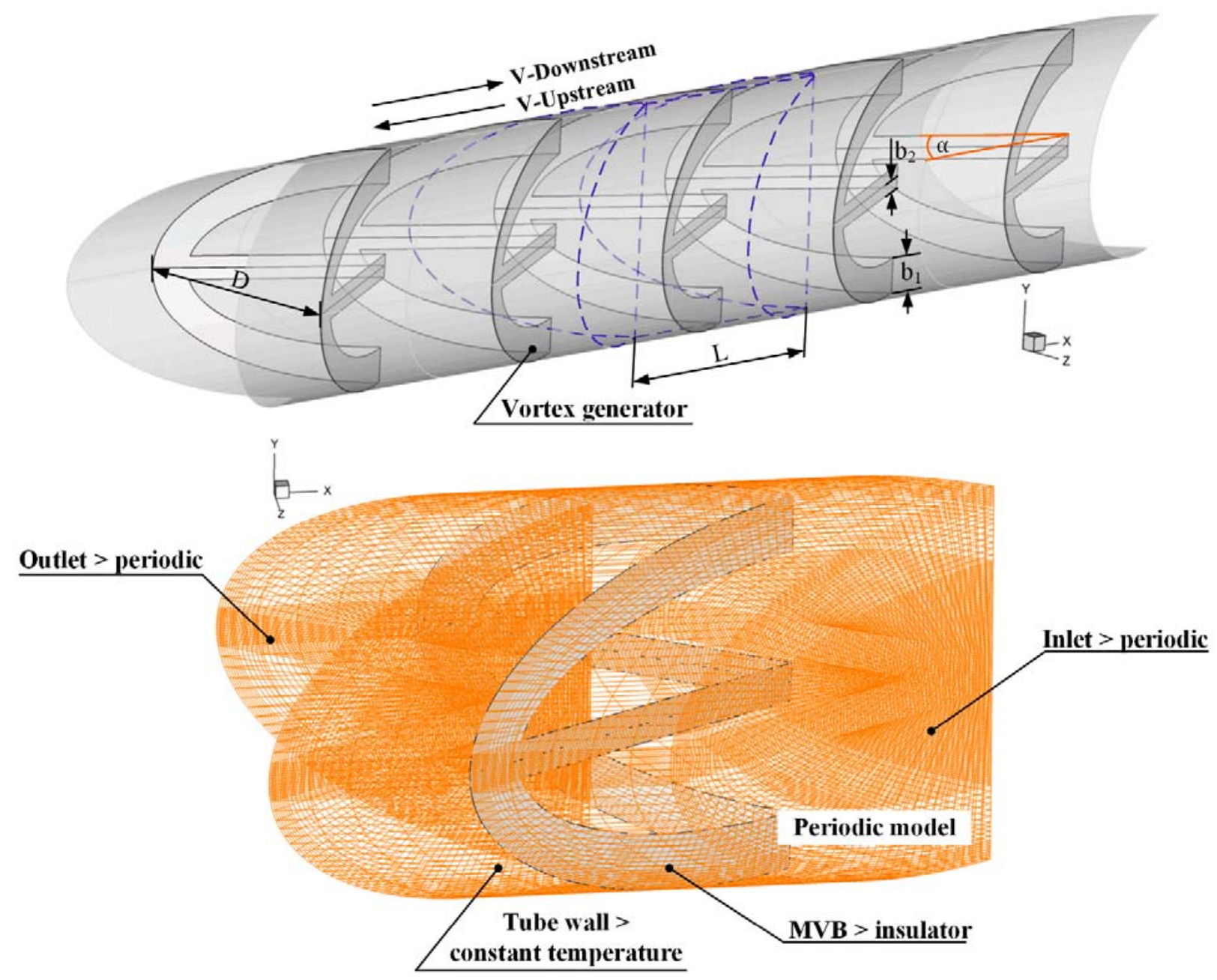

Fig. 1 Computational domain of the CTMVB and boundary conditions.

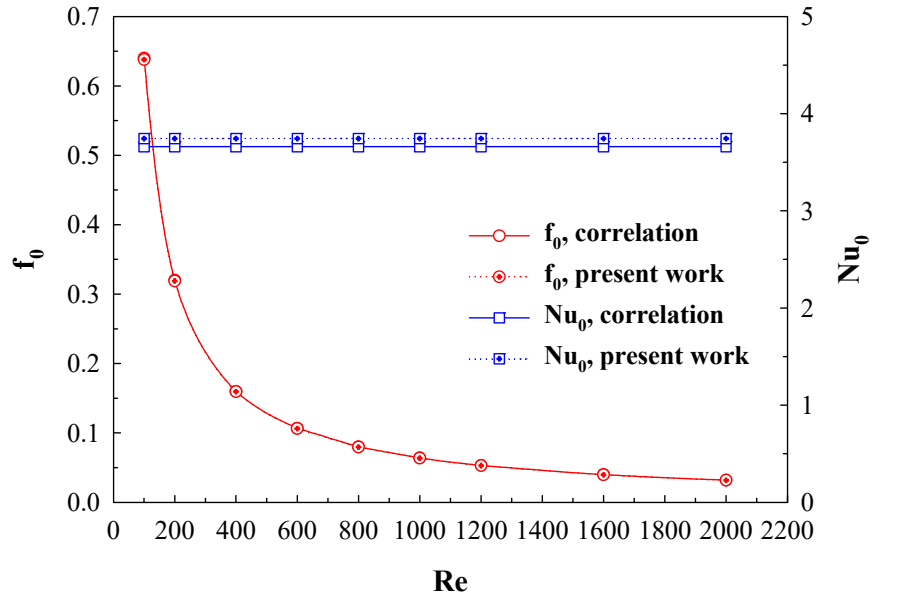

Fig. 2 Numerical validation: Smooth tube validation.
Bai et al. (2019) numerically studied the pressure drop and heat transfer in a pin-fin array installed with rib turbulators. They reported that the rib induces the secondary flow which is a significant cause for the heat transfer increment. They also pointed out that the $90^{\circ}$ rib performs the best overall performance. Jedsadaratanachai et al. (2015) numerically investigated the thermo-hydraulic performance in a circular tube fitted with $45^{\circ} \mathrm{V}$-baffles. The V-baffles were placed in the tube with an inline arrangement. The effects of blockage ratios and flow directions were considered for Reynolds number of about 100 - 2000 (laminar flow). They found that the heat transfer rate and thermal performance in the tube enhances due to the thermal boundary layer disturbance. They also concluded that the maximum thermal enhancement factor is about 3.2. Phila et al. (2020) experimentally studied the effects of flow attack angles for a rectangular channel equipped with inclined baffles. They reported that the flow attack angles of $60^{\circ}$ and $120^{\circ}$ perform the best heat transfer and thermal efficiency. They also concluded that the optimum thermal enhancement factor is around 1.11 at $\mathrm{Re}=9000$. Luan and Phu (2020) experimentally studied the impacts of inclination angles for inclined baffles in a solar air heater. They concluded that the flow attack angles of $60^{\circ}$ and $120^{\circ}$ give the best efficiency. 


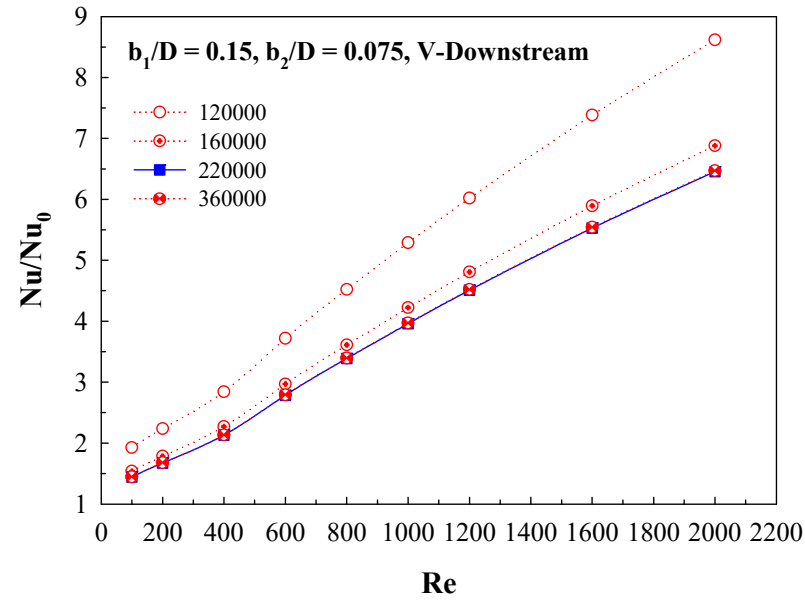

(a)

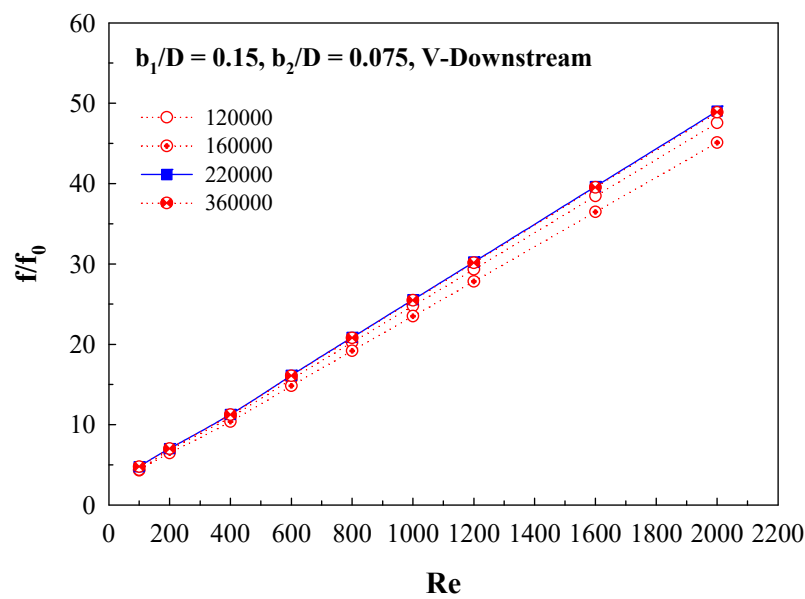

(b)

Fig. 3 Numerical validation: Grid independence for (a) $\mathrm{Nu} / \mathrm{Nu}_{0}$ vs Re and (b) f/fo vs Re.

From the literature reviews above, high performance to improve heat transfer ability and thermal efficiency of ribs or baffles is well known. However, in real systems, it is found that the rib/baffle structures are not stable elements. The rib/baffle installations are quite difficult, especially, in round tube heat exchangers. Therefore, in the present work, the rib/baffle features are modified with the major purposes: 1 . To increase the stability of the rib/baffle structures and 2 . To remain the thermal performance likes as the rib/baffle vortex generators. As our previous works, the V-shaped configurations (Jedsadaratanachai and Boonloi (2017), Boonloi and Jedsadaratanachai (2019a, b), Boonloi and Jedsadaratanachai (2018a, b)) give high thermal performance, thus, the $\mathrm{V}$-shape is chosen for the present research to improve the thermal performance of the heat exchanger tube. The V-baffle, which is inserted at the core of the testing tube, is combined with the V-baffle, which is placed on the tube wall (likes as $\mathrm{V}$-orifice). The new design of the vortex generators is known as "modified V-baffle or MVB". The V-baffle at the middle of the tested tube can help to increase durability of the vortex generator. The circular tube equipped with modified V-baffle (CTMVB) with various baffle sizes, inclination angles and arrangements are numerically studied.

\section{PHYSICAL GEOMETRY OF THE CTMVB}

Fig. 1 illustrates the CTMVB and periodic module. The circular tube diameter (=hydraulic dimeter) is equal to $0.05 \mathrm{~m}$. The MVB is equipped in the tested section with a single pitch ratio, $\mathrm{P} / \mathrm{D}$, of 1 . The baffle height at the middle of the tube is represented with "b2", while the baffle height on the tube wall is represented with "bl". The first blockage ratio, $b_{1} / \mathrm{H}$, and the second blockage ratio, $\mathrm{b}_{2} / \mathrm{H}$, are varied; $\mathrm{b}_{1} / \mathrm{H}=0.05-0.20$ and $\mathrm{b}_{2} / \mathrm{H}=0.025-0.100$. The distance of the periodic segment, $\mathrm{L}$, is equivalent to the round tube diameter, $\mathrm{L}=\mathrm{D}$. The MVB with V-tip directing downstream (V-Downstream) and with V-tip directing upstream (V-Upstream) are arranged in the tested section. The flow attack angles of $20^{\circ}$ and $30^{\circ}$ are selected in the present investigation. The laminar flow scheme with the Reynolds number (based on the round tube diameter, $\mathrm{D}$, at the inlet condition) in the range about $100-2000$ is considered.

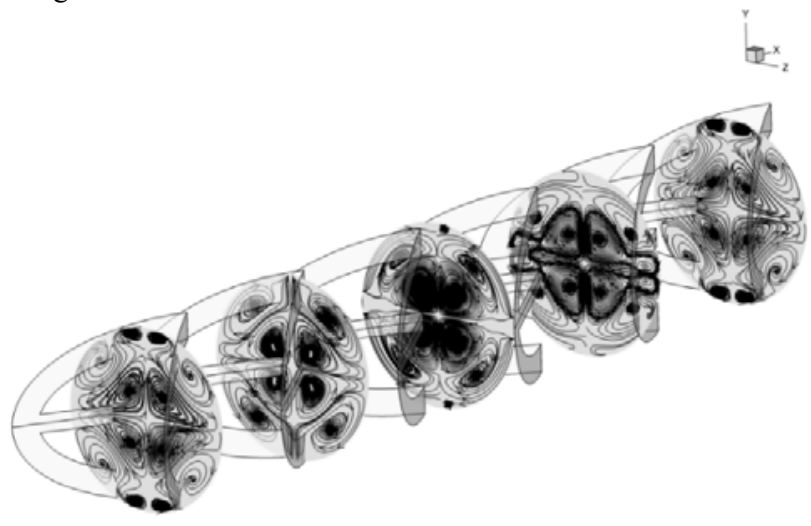

(a)

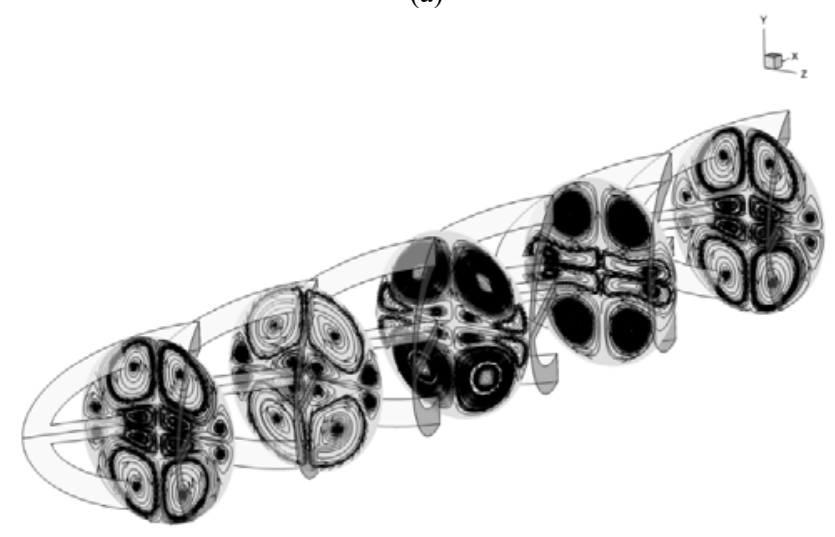

(b)

Fig. 4 Streamlines in $y-z$ planes in the CTMVB at $b_{1} / D=0.15, b_{2} / D$ $=0.05, \operatorname{Re}=800$ and $\alpha=30^{\circ}$ for (a) V-Downstream and (b) V-Upstream.

\section{ASSUMPTION AND BOUNDARY CONDITION}

The assumptions for the present research can be concluded as follows.

- The flow and heat transfer profiles in the CTMVB are steady in three dimensions.

- $\quad$ Forced convective heat transfer is counted, while natural convection and radiation heat transfer are disregarded.

- The tested fluid is air. The thermal properties of the air are supposed to be constant at average bulk mean temperature. The air temperature of $300 \mathrm{~K}(\mathrm{Pr}=0.707)$ is set for the study.

- Body force and viscous dissipation are ignored.

The boundary conditions for the computational domain of the CTMVB can be summarized as follows.

- The entry and exit regimes of the domain are set with periodic condition.

- The tube wall is set with uniform temperature of $310 \mathrm{~K}$.

- The MVB are supposed to be an insulator or constant heat flux of about $0 \mathrm{~W} / \mathrm{m}^{2}$.

- No slip wall condition applies for the whole sides of the computational domain. 


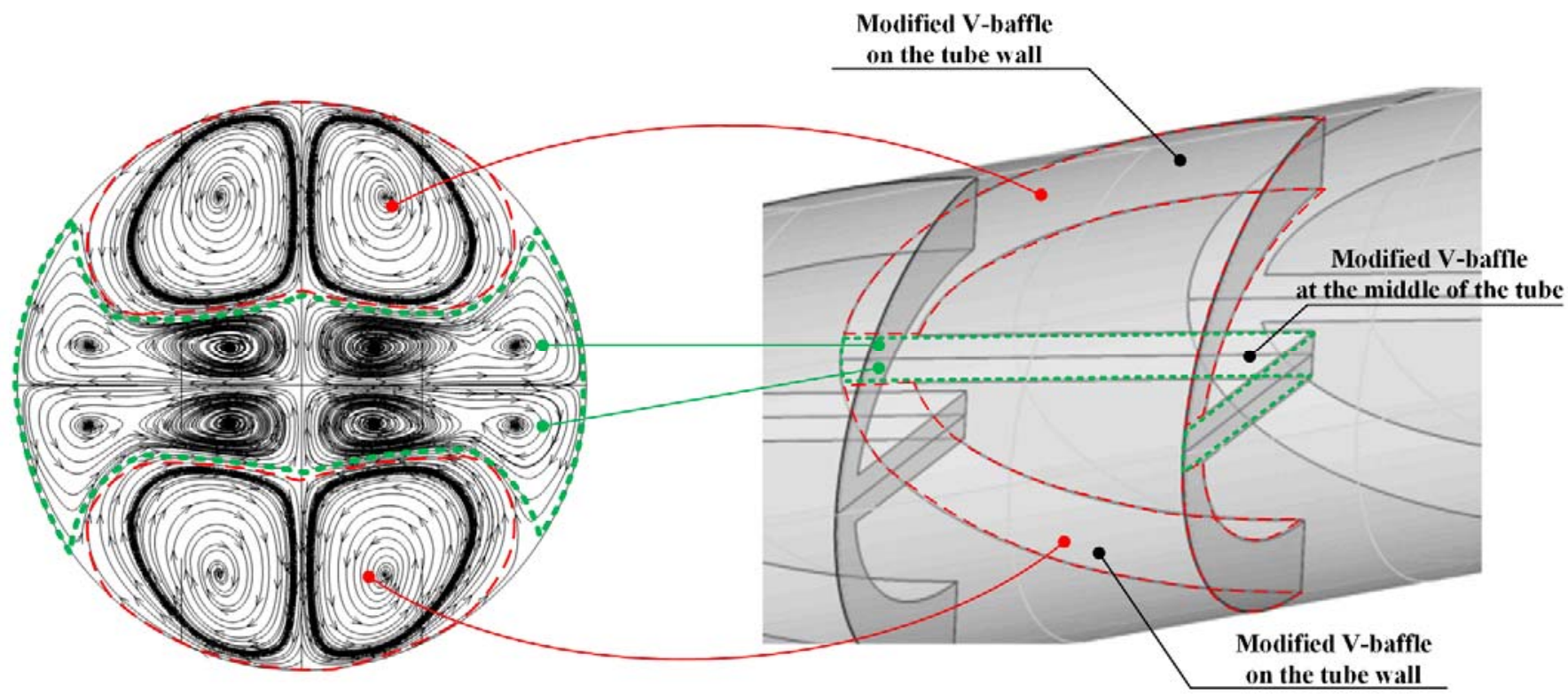

Fig. 5 The generation of the vortex flows in transverse planes by each part of the MVB.

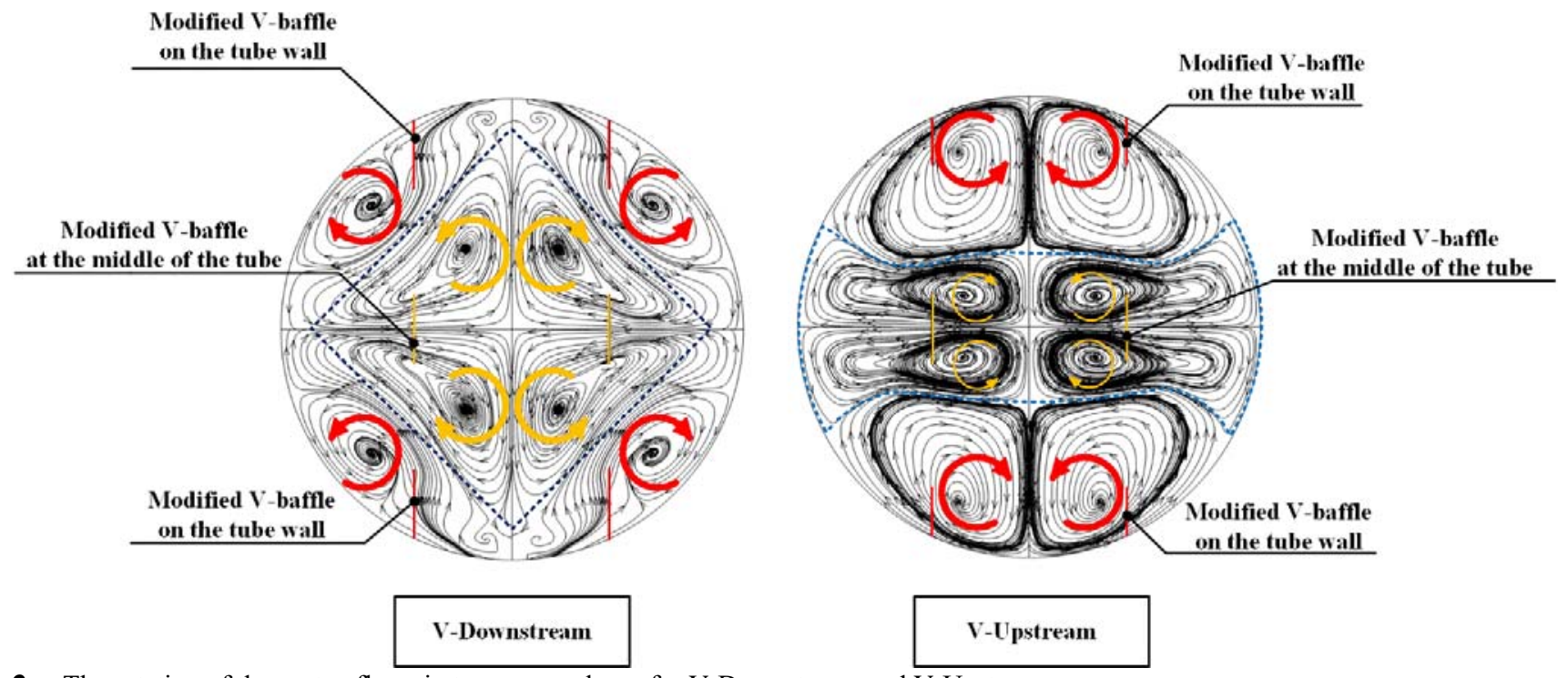

Fig. 6 The rotation of the vortex flows in transverse planes for V-Downstream and V-Upstream.

\section{MATHEMATICAL FOUNDATION AND NUMERICAL METHOD}

A commercial code is selected for the present investigation. The finite volume method with SIMPLE algorithm is picked to analyze the present work. The computational domain is solved by the continuity, the Navier-Stokes and the energy equations which can be written as equations 1,2 and 3 , respectively.

Continuity equation:

$\frac{\partial}{\partial x_{i}}\left(\rho u_{i}\right)=0$

Momentum equation:

$\frac{\partial\left(\rho u_{i} u_{j}\right)}{\partial x_{j}}=-\frac{\partial p}{\partial x_{i}}+\frac{\partial}{\partial x_{j}}\left[\mu\left(\frac{\partial u_{i}}{\partial x_{j}}+\frac{\partial u_{j}}{\partial x_{i}}\right)\right]$ $\frac{\partial}{\partial x_{i}}\left(\rho u_{i} T\right)=\frac{\partial}{\partial x_{j}}\left(\Gamma \frac{\partial T}{\partial x_{j}}\right)$

where, $\Gamma$ is the thermal diffusivity and is written as follows:

$\Gamma=\frac{\mu}{\operatorname{Pr}}$

The continuity and the momentum equations are discretized by power law scheme, while the energy equation is discretized by QUICK scheme. For the simulation, the solutions are considered to be converged when the normalized residual values are less than $10^{-5}$ for all variables, but less than $10^{-9}$ only for the energy equation.

The air speed, heat transfer rate, pressure loss and thermal efficiency are presented in terms of Reynolds number, Nusselt number, friction factor and thermal enhancement factor, respectively.

The Reynolds number can be calculated by equation 5 .

Energy equation: 
$\operatorname{Re}=\frac{\rho \bar{u} D}{\mu}$

The friction factor is calculated by equation 6 .

$$
f=\frac{(\Delta p / L) D}{\frac{1}{2} \rho \bar{u}^{2}}
$$

The local Nusselt number and average Nusselt number can be estimated by equations 7 and 8 , respectively.

$$
N u_{x}=\frac{h_{x} D}{k}
$$

$$
N u=\frac{1}{L} \int N u_{x} \partial x
$$

The thermal enhancement factor (TEF) can be determined by equation 9.

$$
T E F=\left.\frac{h}{h_{0}}\right|_{p p}=\left.\frac{N u}{N u_{0}}\right|_{p p}=\left(N u / N u_{0}\right) /\left(f / f_{0}\right)^{1 / 3}
$$

The Nusselt number and friction factor for the smooth round tube are written by "Nu" and "fo", respectively.

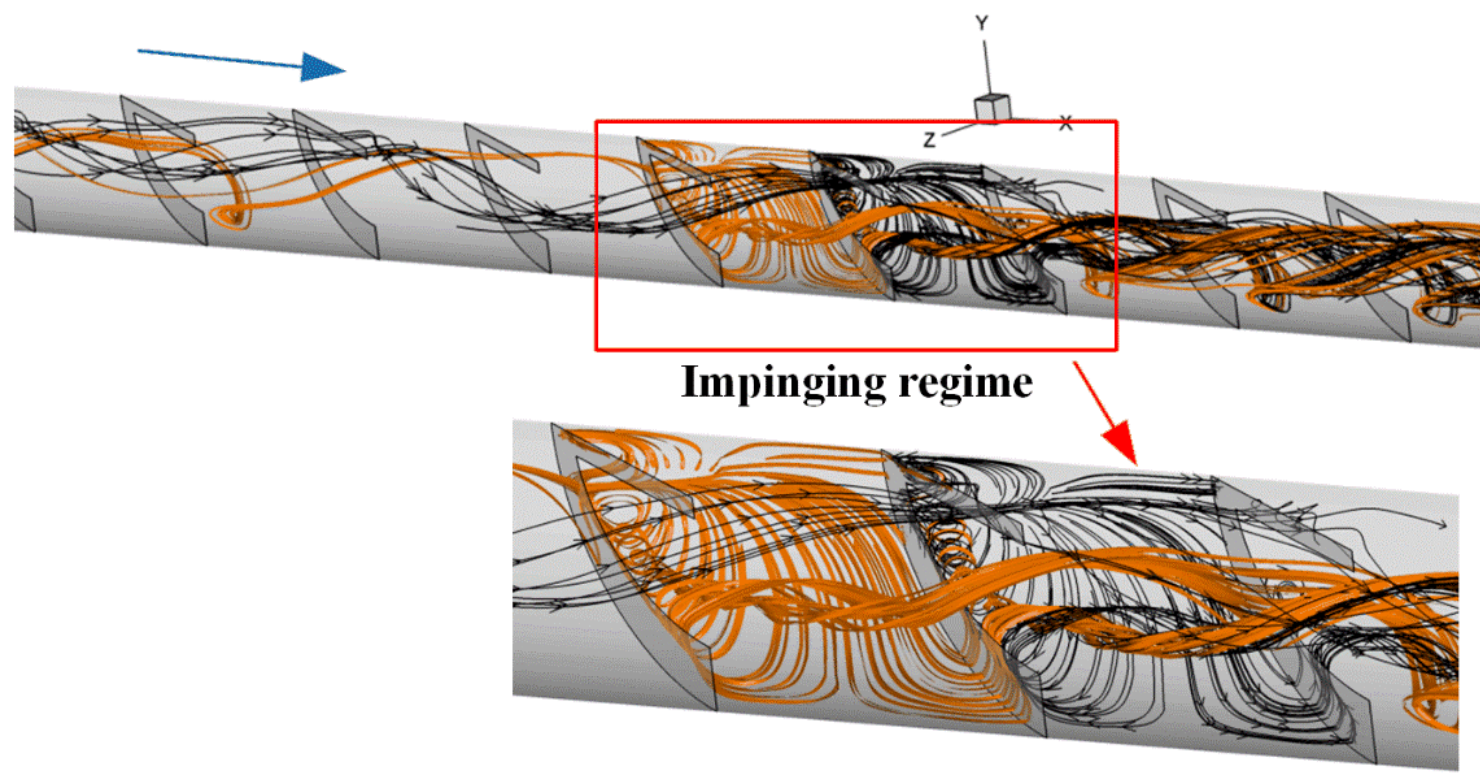

(a)

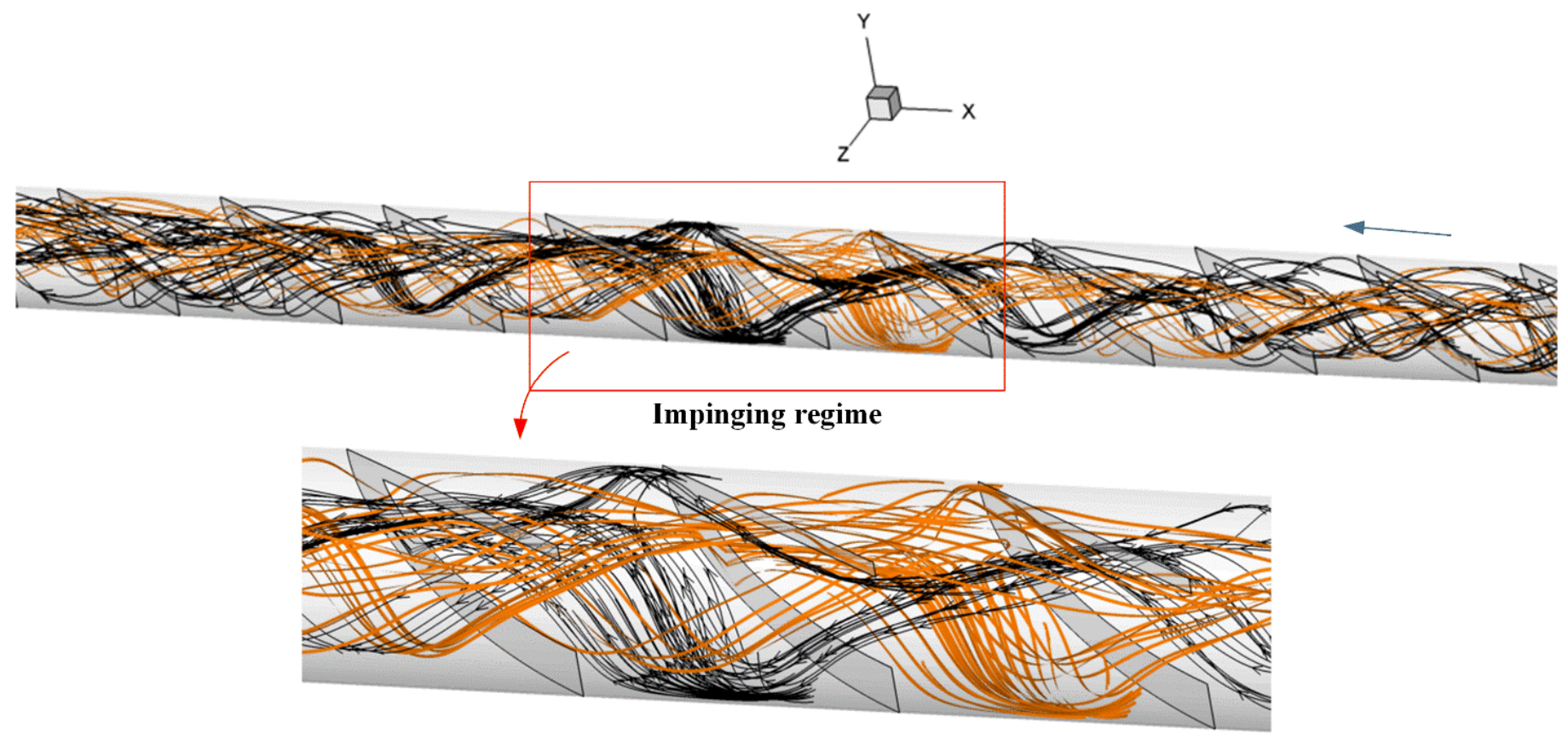

(b)

Fig. 7 The longitudinal vortex flows in the CTMVB for (a) V-Downstream and (b) V-Upstream. 


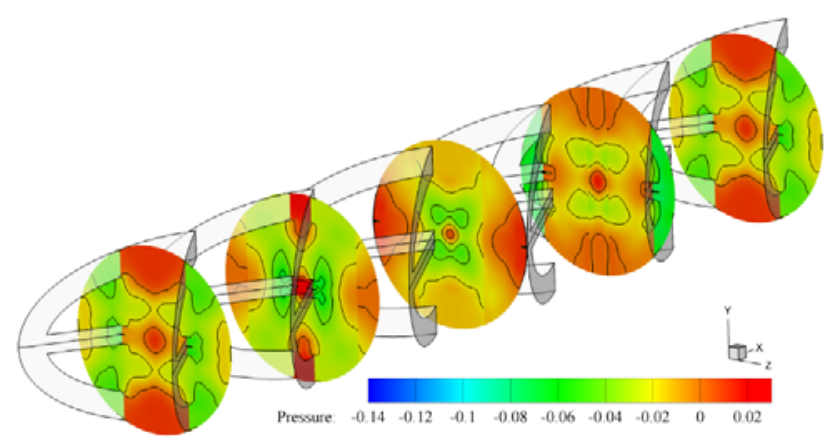

(a)

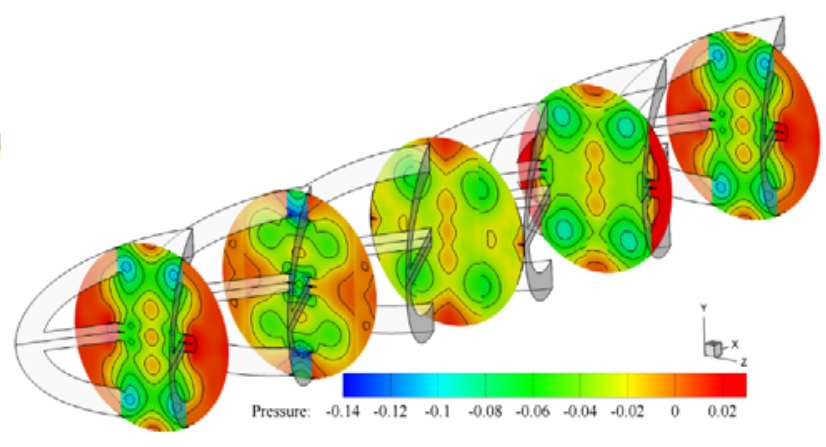

(b)

Fig. 8 Pressure contours in $y-z$ planes in the CTMVB at $b_{1} / D=0.15, b_{2} / D=0.05, \operatorname{Re}=800$ and $\alpha=30^{\circ}$ for (a) V-Downstream and (b) VUpstream.

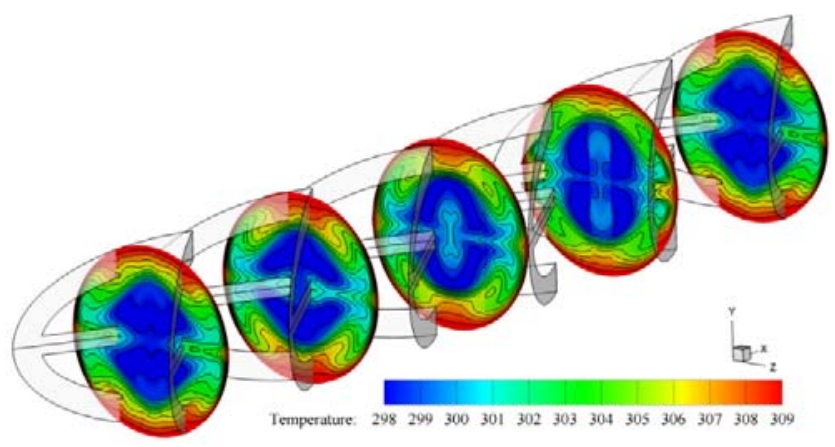

(a)

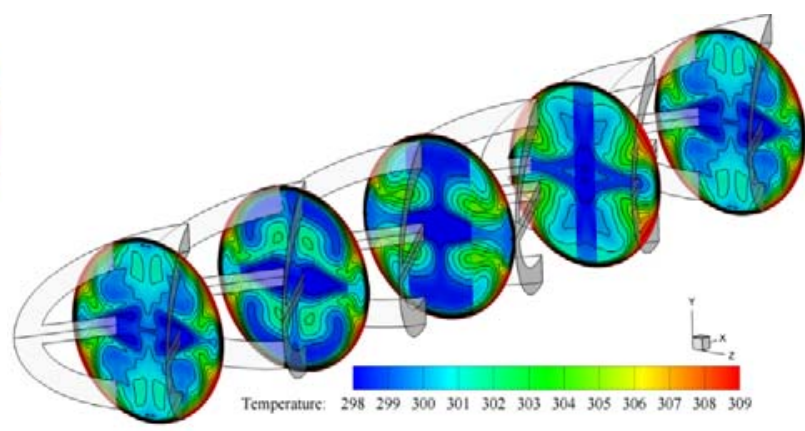

(b)

Fig. 9 Temperature distributions in $y-z$ planes in the CTMVB at $b_{1} / D=0.15, b_{2} / D=0.05, R e=800$ and $\alpha=30^{\circ}$ for (a) V-Downstream and (b) VUpstream.
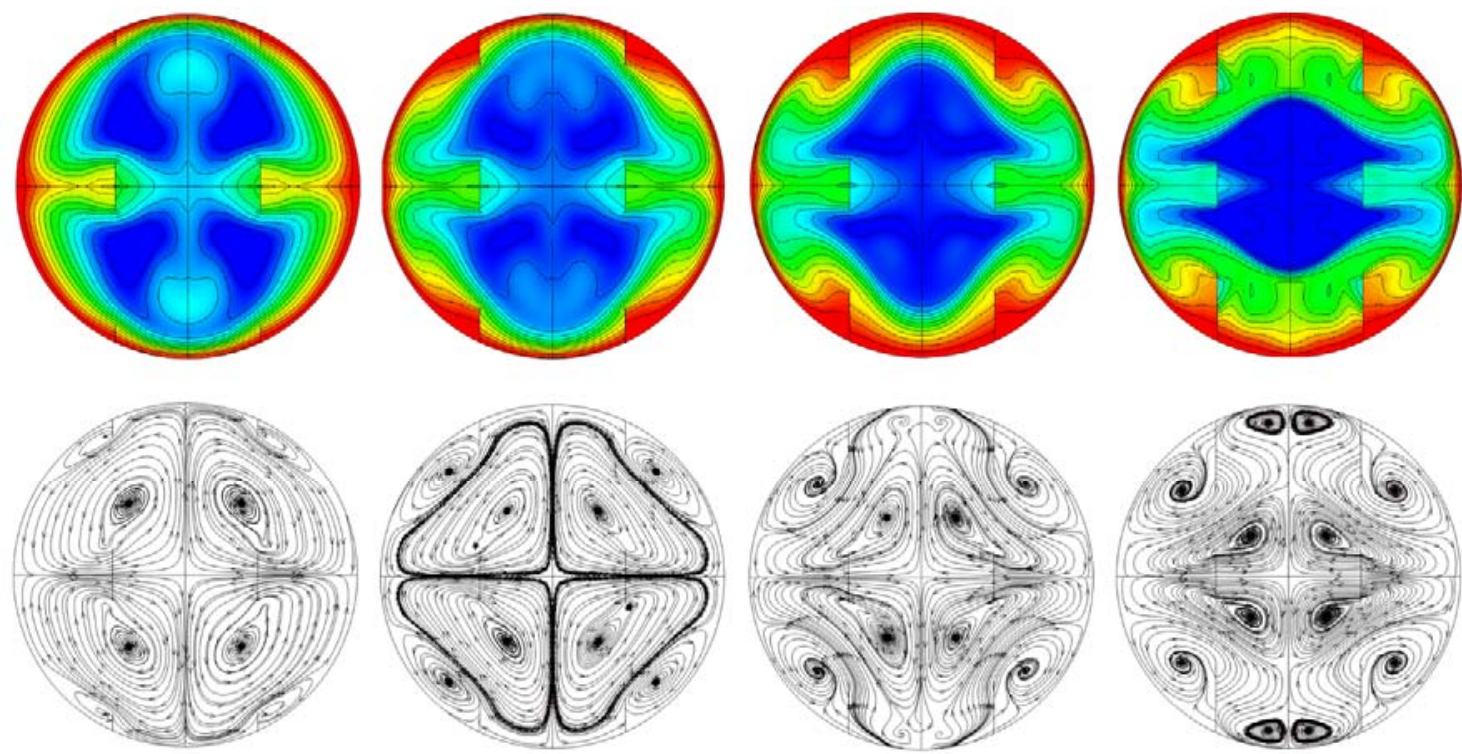

$$
\mathrm{b}_{1} / \mathrm{D}=\mathbf{0 . 0 5}
$$

$$
\mathrm{b}_{1} / \mathrm{D}=\mathbf{0 . 1 0}
$$

$\mathbf{b}_{1} / \mathrm{D}=\mathbf{0 . 1 5}$

$b_{1} / D=0.20$

$\mathrm{b}_{2} / \mathrm{D}=\mathbf{0 . 0 7 5}$

V-Downstream

Fig. 10 Flow and heat transfer patterns in the CTMVB with V-Downstream arrangement at $b_{2} / D=0.075$ and various $b_{1} / D$ for $R e=600$ and $\alpha=$ $30^{\circ}$. 

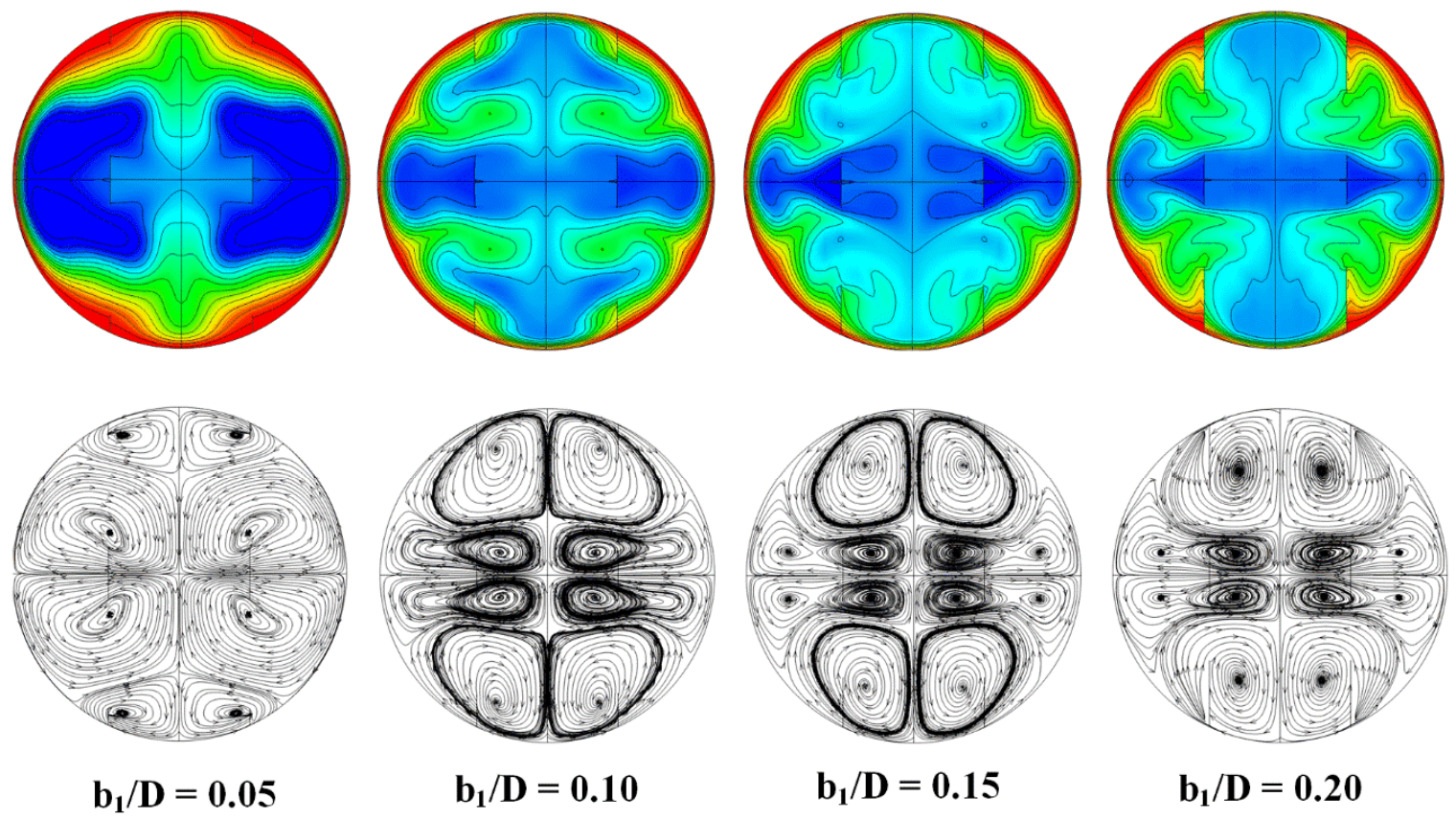

$\mathbf{b}_{1} / \mathrm{D}=\mathbf{0 . 1 0}$

$b_{1} / \mathbf{D}=\mathbf{0 . 1 5}$

$b_{1} / D=0.20$

\section{$\mathbf{b}_{2} / \mathrm{D}=\mathbf{0 . 0 7 5}$}

V-Upstream

Fig. 11 Flow and heat transfer patterns in the CTMVB with V-Upstream arrangement at $b_{2} / D=0.075$ and various $b_{1} / D$ for $R e=600$ and $\alpha=30^{\circ}$.
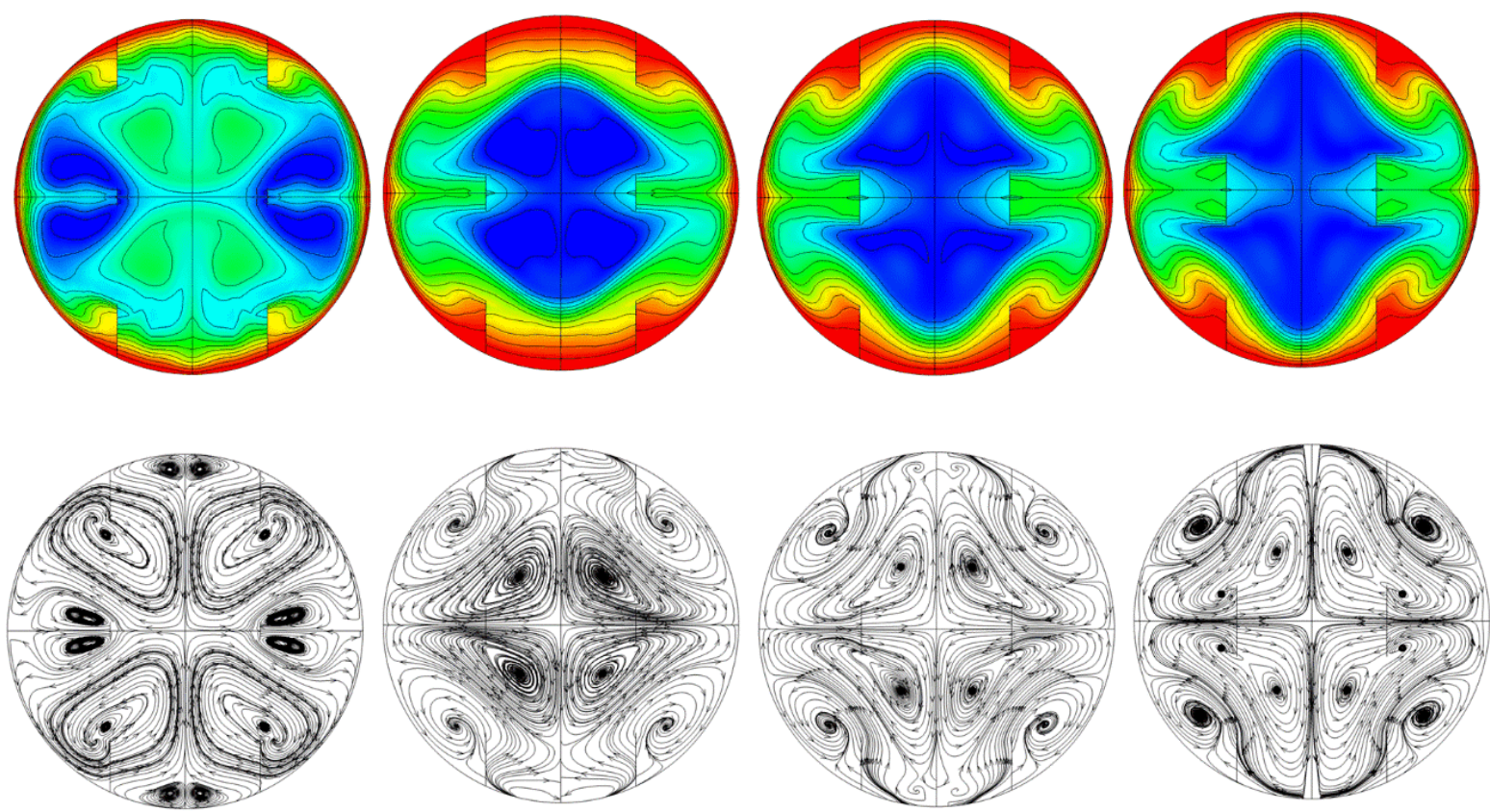

$b_{2} / D=0.025$

$\mathbf{b}_{2} / \mathrm{D}=\mathbf{0 . 0 5}$

$\mathbf{b}_{2} / \mathrm{D}=\mathbf{0 . 0 7 5}$

$\mathrm{b}_{2} / \mathrm{D}=\mathbf{0 . 1}$

\section{$\mathrm{b}_{1} / \mathrm{D}=\mathbf{0 . 1 5}$ V-Downstream}

Fig. 12 Flow and heat transfer patterns in the CTMVB with V-Downstream arrangement at $b_{1} / D=0.15$ and various $b_{2} / D$ for $R e=600$ and $\alpha=30^{\circ}$. 

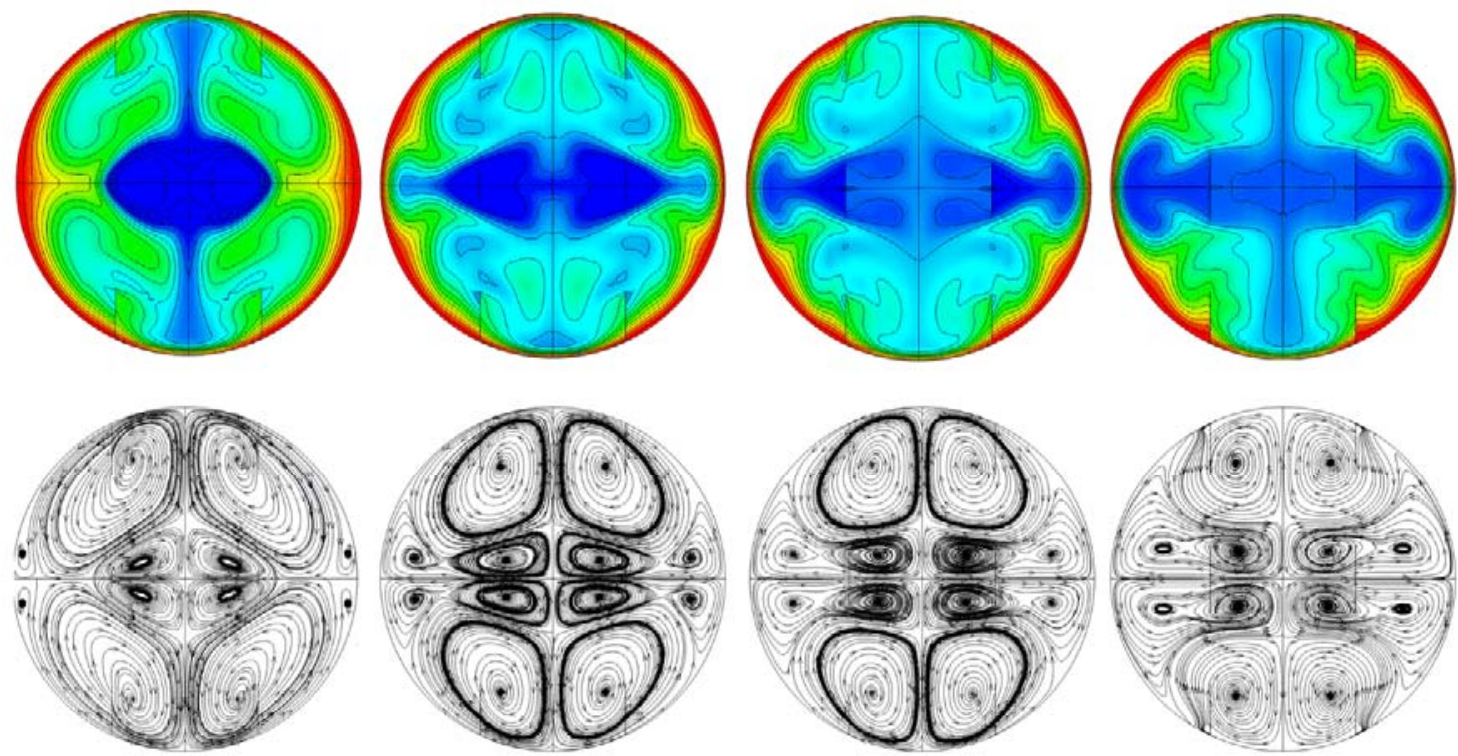

$\mathbf{b}_{2} / \mathbf{D}=\mathbf{0 . 0 2 5}$

$b_{2} / D=0.05$

$b_{2} / D=0.075$

$b_{2} / D=0.1$

$b_{1} / D=0.15$,
V-Upstream

Fig. 13 Flow and heat transfer patterns in the CTMVB with V-Upstream arrangement at $b_{1} / D=0.15$ and various $b_{2} / D$ for $R e=600$ and $\alpha=30^{\circ}$.
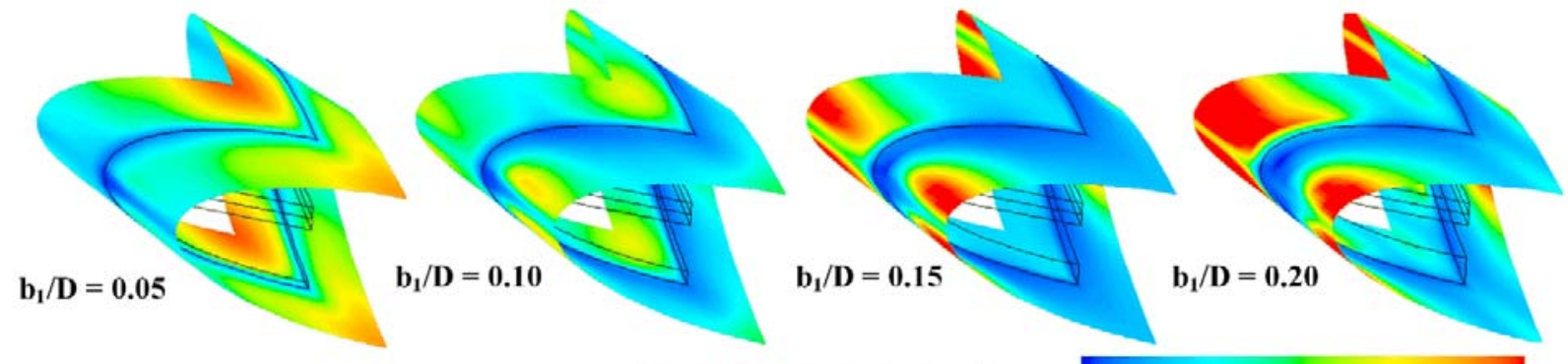

$$
\begin{gathered}
\mathbf{b}_{2} / \mathrm{D}=\mathbf{0 . 0 7 5}, \\
\text { V-Downstream }
\end{gathered}
$$

$\mathrm{Nu}_{\mathbf{x}}: \mathbf{0}$

$\mathbf{b}_{1} / \mathbf{D}=\mathbf{0 . 2 0}$

Fig. 14 Nusselt number contours in the CTMVB with V-Downstream arrangement at $b_{2} / D=0.075$ and various $b_{1} / D$ for $R e=600$ and $\alpha=30^{\circ}$.
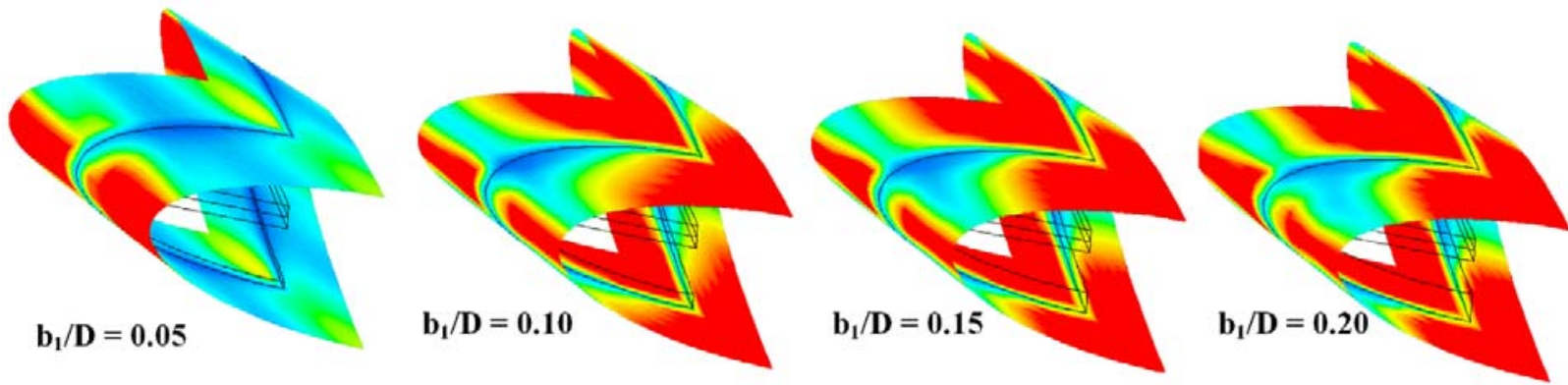

$$
\begin{aligned}
& \mathbf{b}_{2} / \mathrm{D}=0.075 \\
& \text { V-Upstream }
\end{aligned}
$$

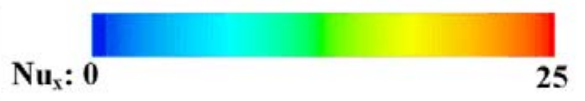

Fig. 15 Nusselt number contours in the CTMVB with V-Upstream arrangement at $b_{2} / D=0.075$ and various $b_{1} / D$ for $R e=600$ and $\alpha=30^{\circ}$. 

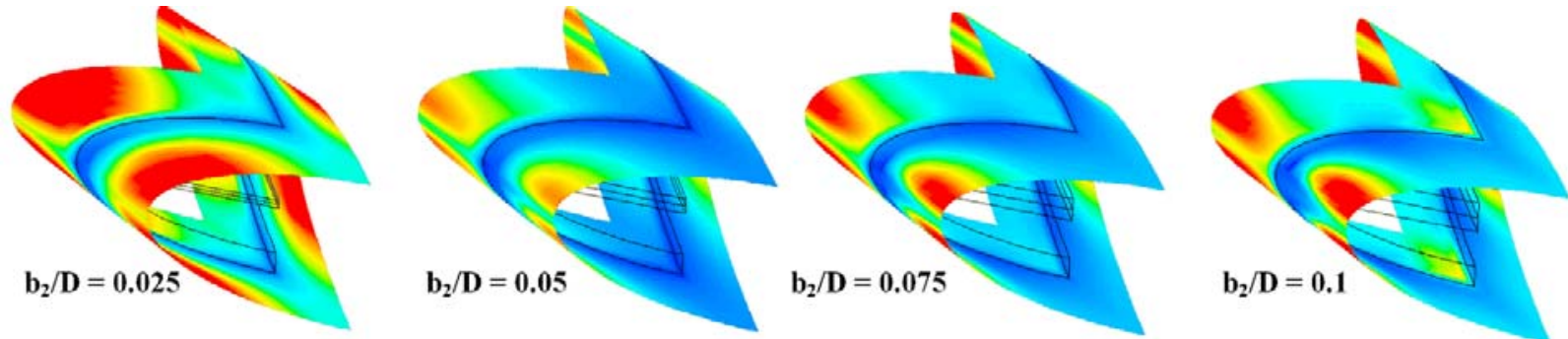

$\mathrm{b}_{1} / \mathrm{D}=\mathbf{0 . 1 5}$, V-Downstream

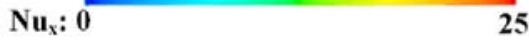

Fig. 16 Nusselt number contours in the CTMVB with V-Downstream arrangement at $b_{1} / D=0.15$ and various $b_{2} / D$ for $R e=600$ and $\alpha=30^{\circ}$.
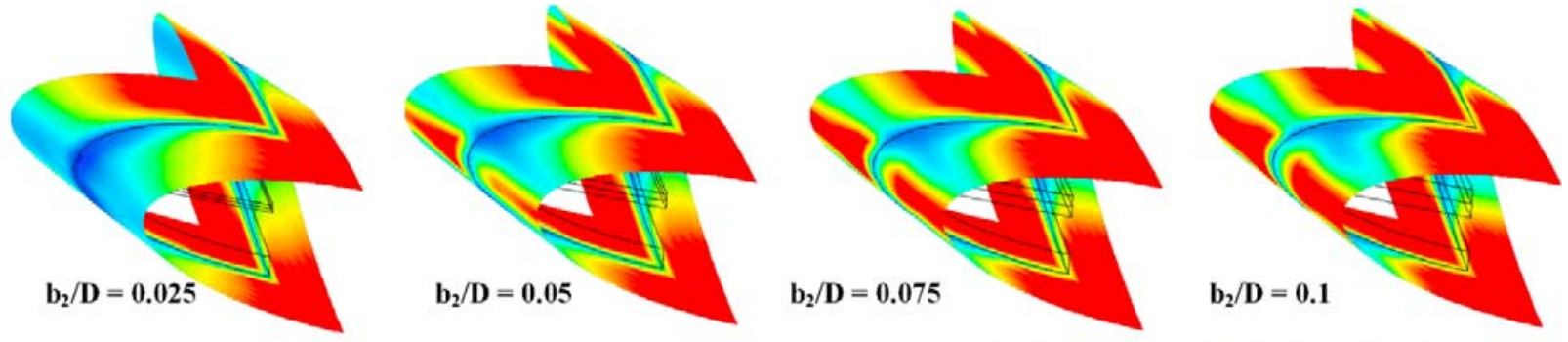

\section{$\mathbf{b}_{1} / \mathbf{D}=\mathbf{0 . 1 5}$ V-Upstream}

$\mathrm{Nu}_{\mathbf{x}} \mathbf{0}$

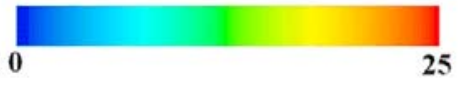

Fig. 17 Nusselt number contours in the CTMVB with V-Upstream arrangement at $b_{1} / D=0.15$ and various $b_{2} / D$ for $R e=600$ and $\alpha=30^{\circ}$.

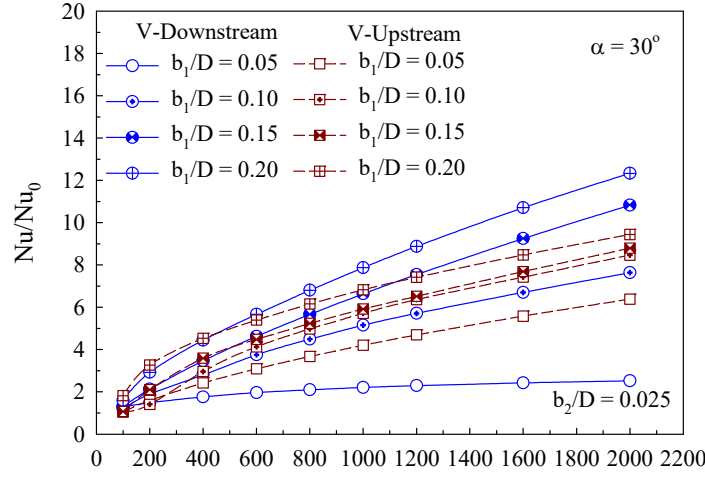

$\mathrm{Re}$

(a)

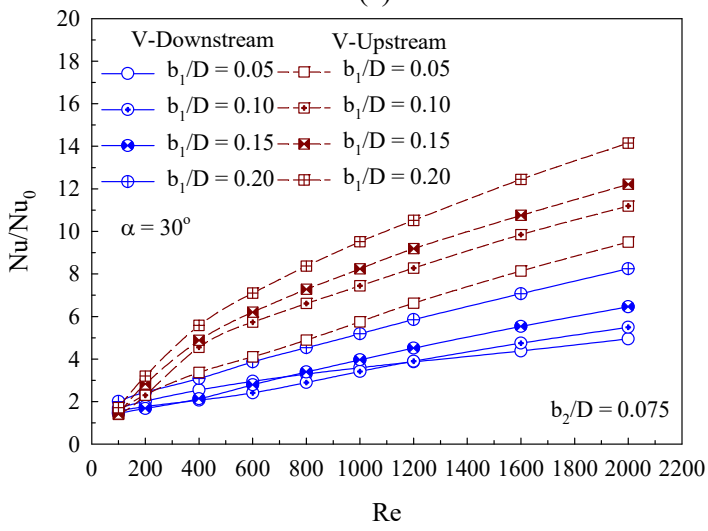

(c)

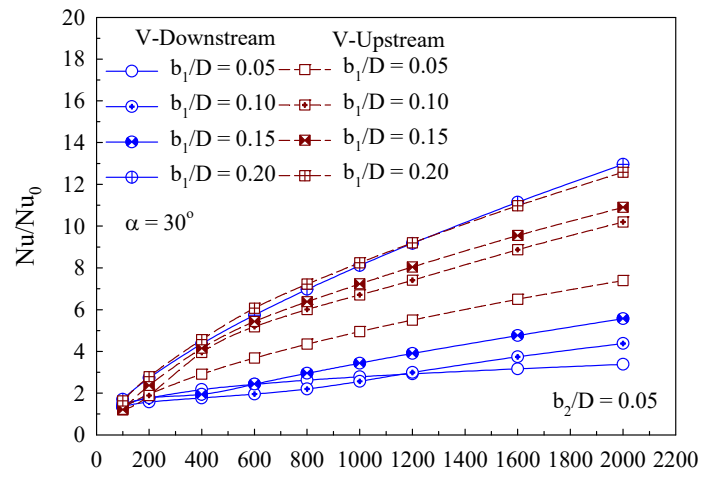

$\operatorname{Re}$

(b)

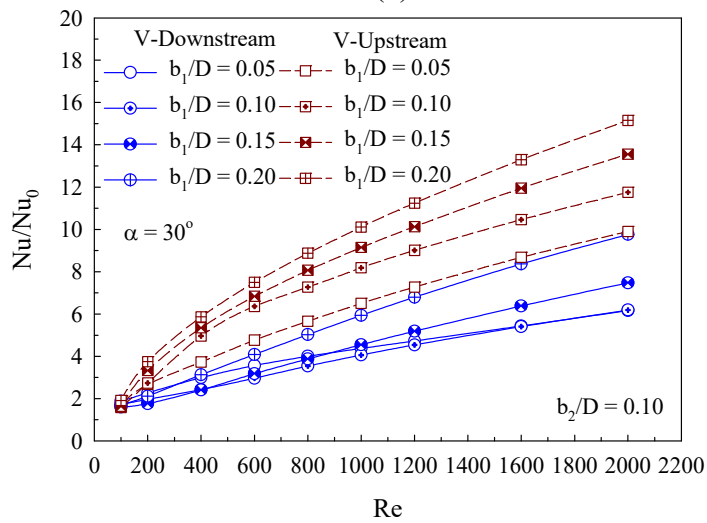

(d)

Fig. $18 \mathrm{Nu} / \mathrm{Nu}_{0}$ vs $\mathrm{Re}$ of $\alpha=30^{\circ}$ for (a) $\mathrm{b}_{2} / \mathrm{D}=0.025$, (b) $\mathrm{b}_{2} / \mathrm{D}=0.05$, (c) $\mathrm{b}_{2} / \mathrm{D}=0.075$ and (d) $\mathrm{b}_{2} / \mathrm{D}=0.1$. 


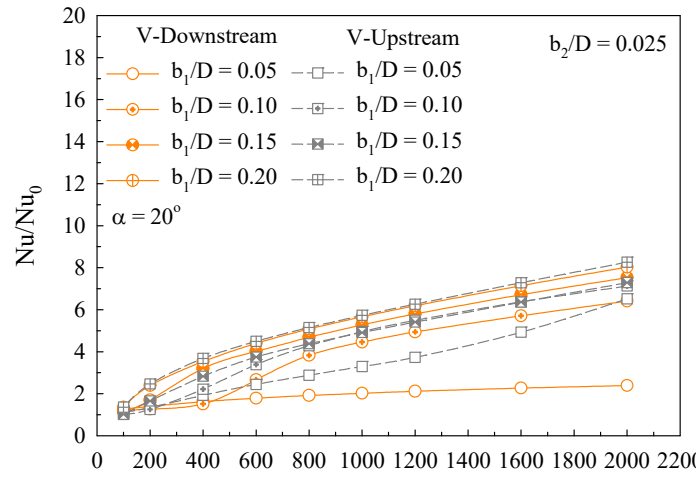

$\mathrm{Re}$

(a)

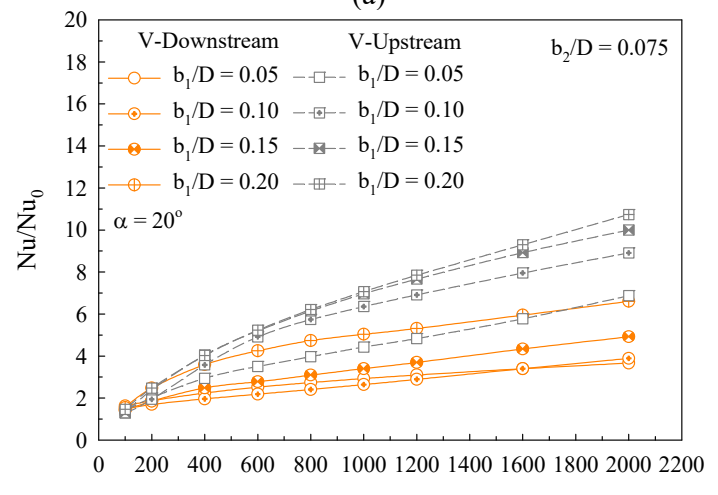

$\mathrm{Re}$

(c)

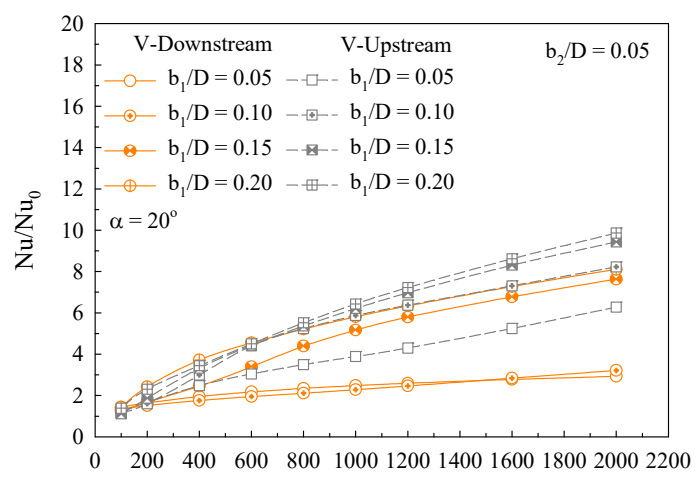

$\mathrm{Re}$

(b)

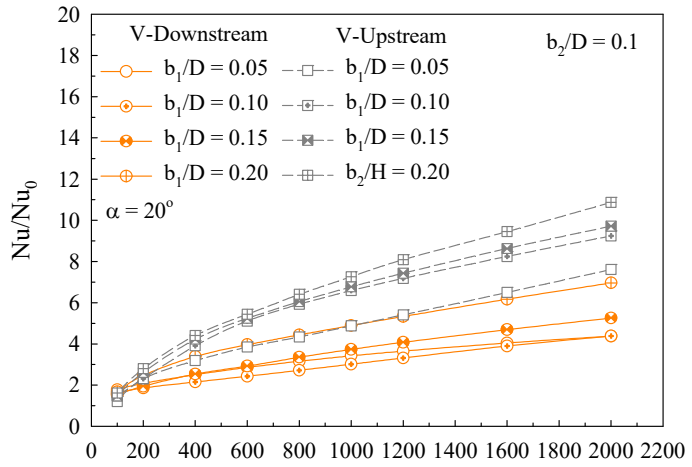

$\mathrm{Re}$

(d)

Fig. $19 \mathrm{Nu} / \mathrm{Nu}_{0}$ vs $\mathrm{Re}$ of $\alpha=20^{\circ}$ for (a) $\mathrm{b}_{2} / \mathrm{D}=0.025$, (b) $\mathrm{b}_{2} / \mathrm{D}=0.05$, (c) $\mathrm{b}_{2} / \mathrm{D}=0.075$ and (d) $b_{2} / \mathrm{D}=0.1$.

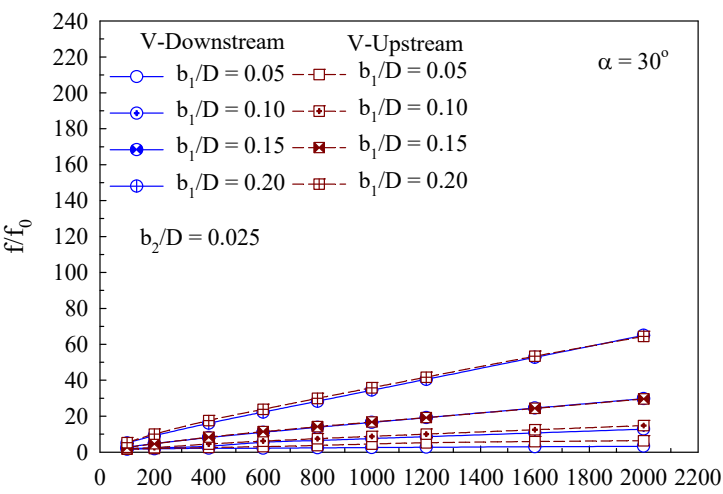

$\mathrm{Re}$

(a)

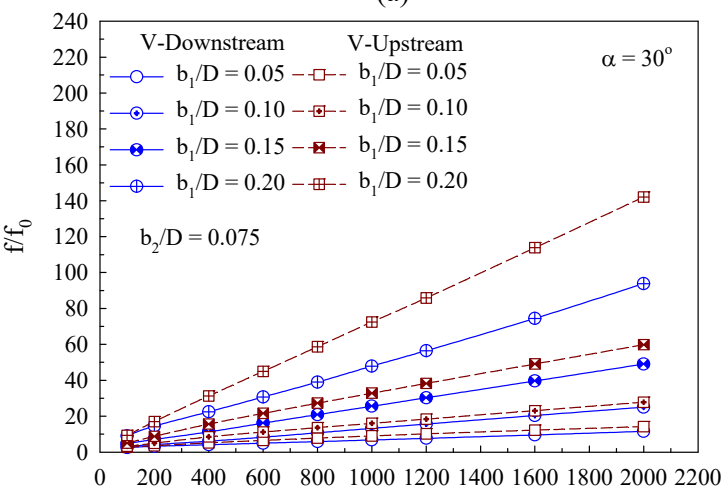

$\operatorname{Re}$

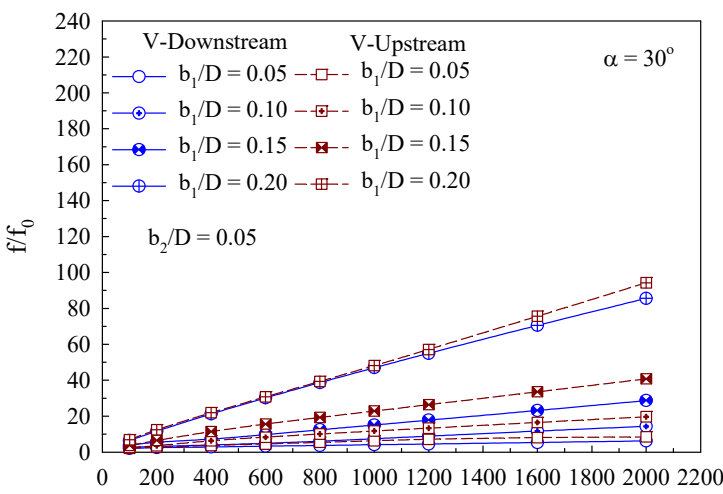

$\operatorname{Re}$

(b)

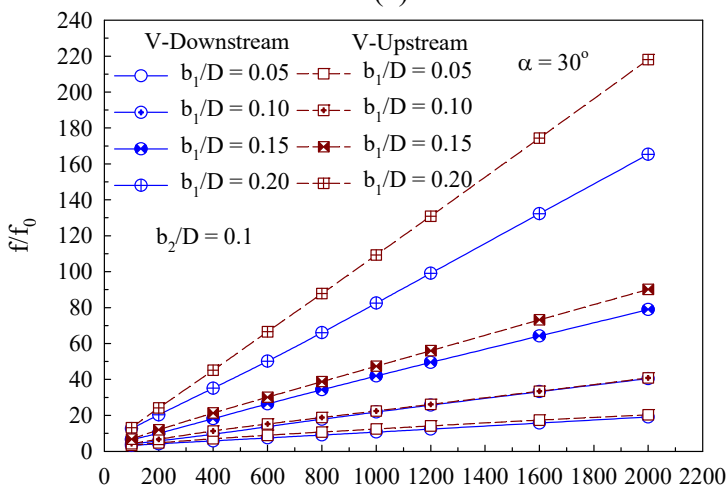

$\mathrm{Re}$

(d)

Fig. $20 \mathrm{f} / \mathrm{f}_{0}$ vs $\operatorname{Re}$ of $\alpha=30^{\circ}$ for (a) $b_{2} / D=0.025$, (b) $b_{2} / D=0.05$, (c) $b_{2} / D=0.075$ and (d) $b_{2} / D=0.1$. 


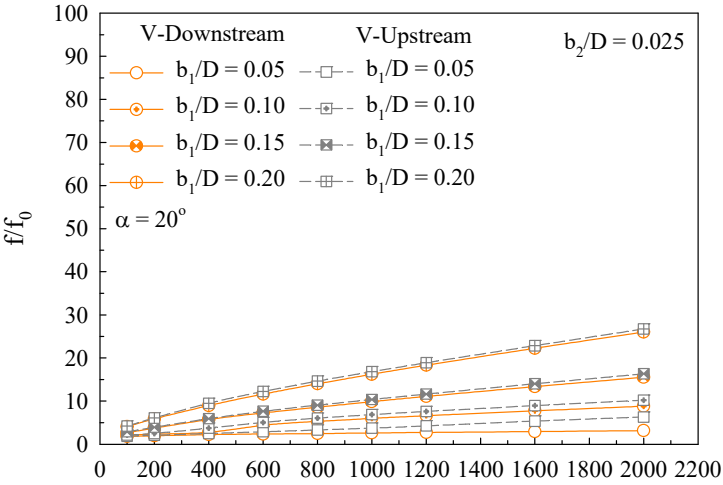

(a)

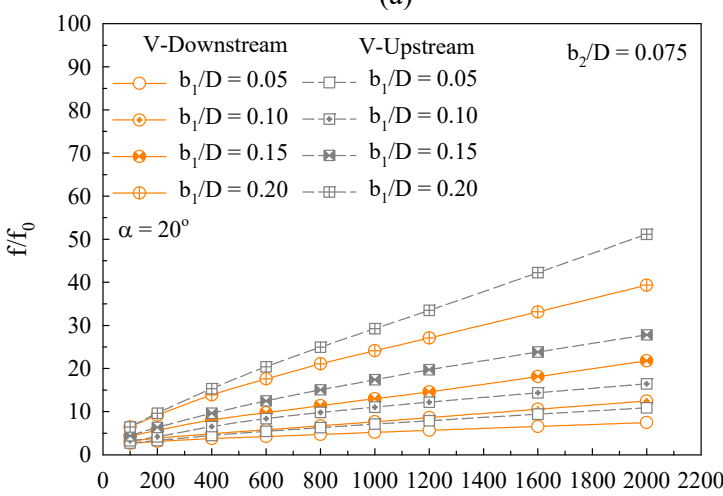

$\mathrm{Re}$

(c)

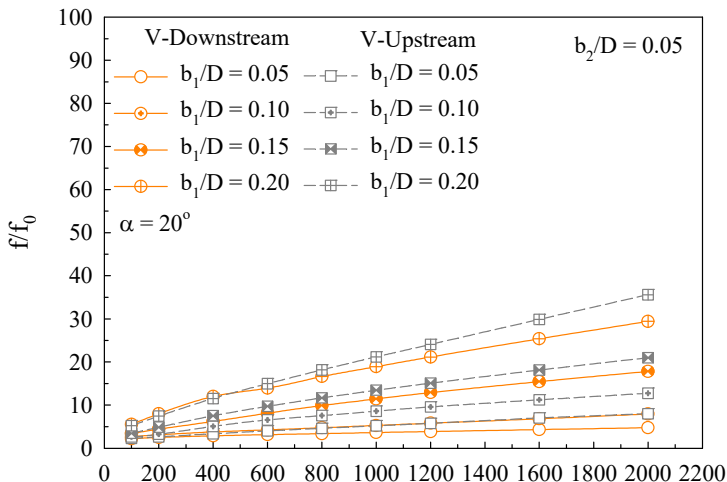

$\operatorname{Re}$

(b)

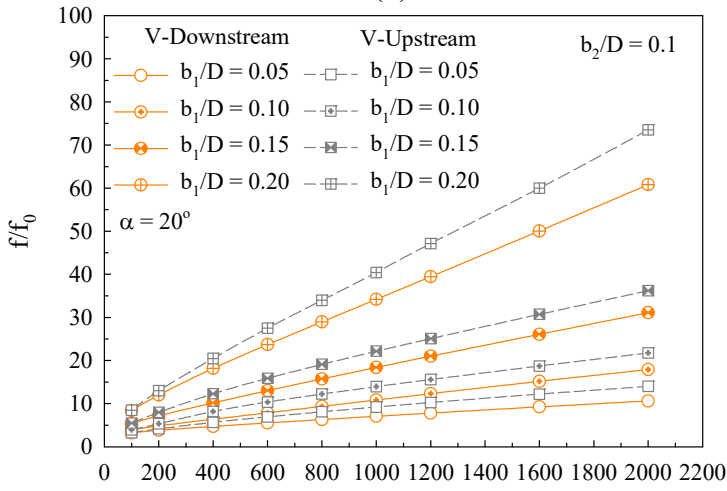

$\mathrm{Re}$

(d)

Fig. $21 \mathrm{f} / \mathrm{f}_{0}$ vs $\operatorname{Re}$ of $\alpha=20^{\circ}$ for (a) $b_{2} / D=0.025$, (b) $b_{2} / D=0.05$, (c) $b_{2} / D=0.075$ and (d) $b_{2} / D=0.1$.

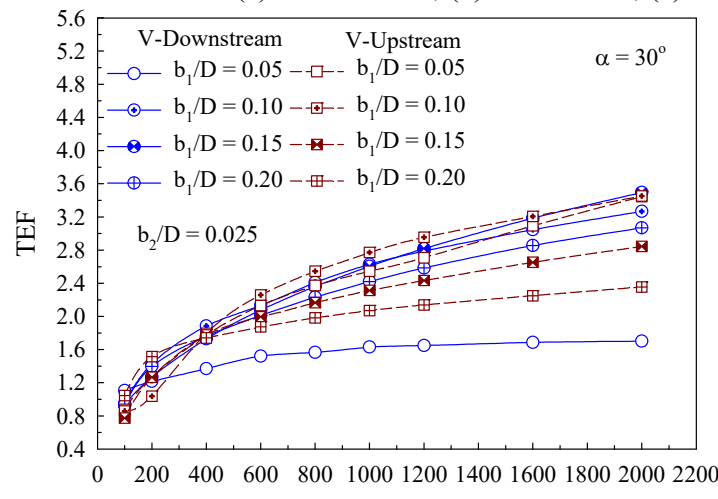

$\mathrm{Re}$

(a)

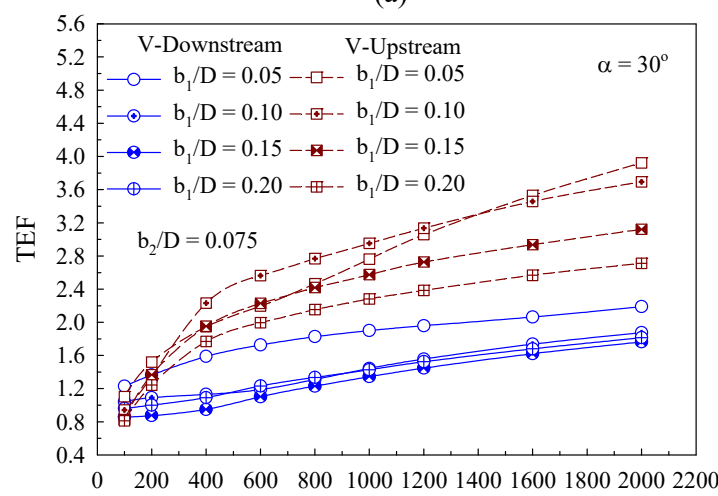

$\mathrm{Re}$

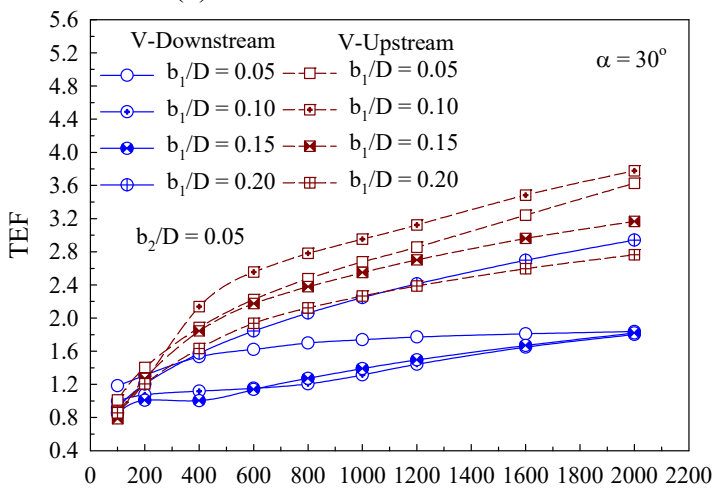

$\mathrm{Re}$

(b)

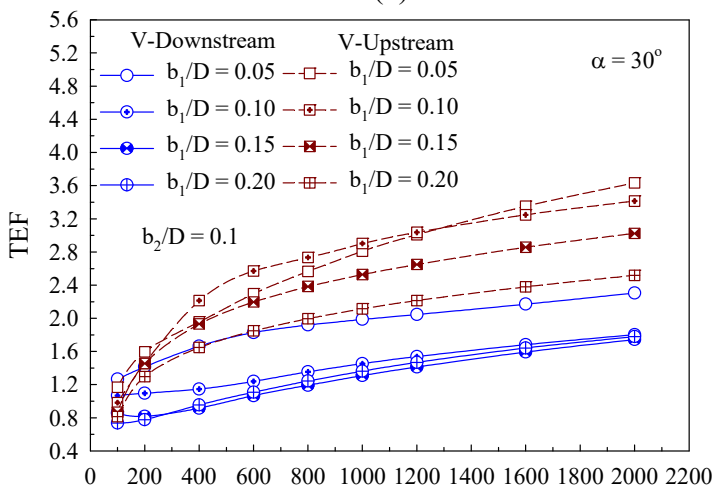

$\operatorname{Re}$

(d)

Fig. 22 TEF vs $\operatorname{Re}$ of $\alpha=30^{\circ}$ for (a) $b_{2} / D=0.025$, (b) $b_{2} / D=0.05$, (c) $b_{2} / D=0.075$ and (d) $b_{2} / D=0.1$. 


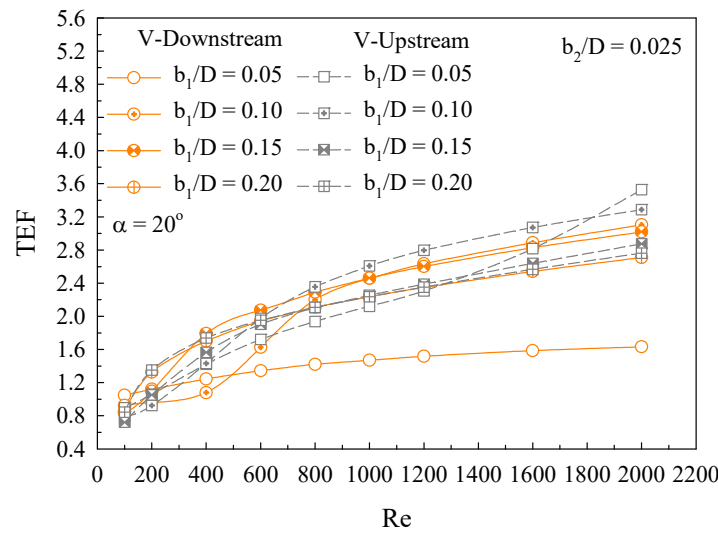

(a)

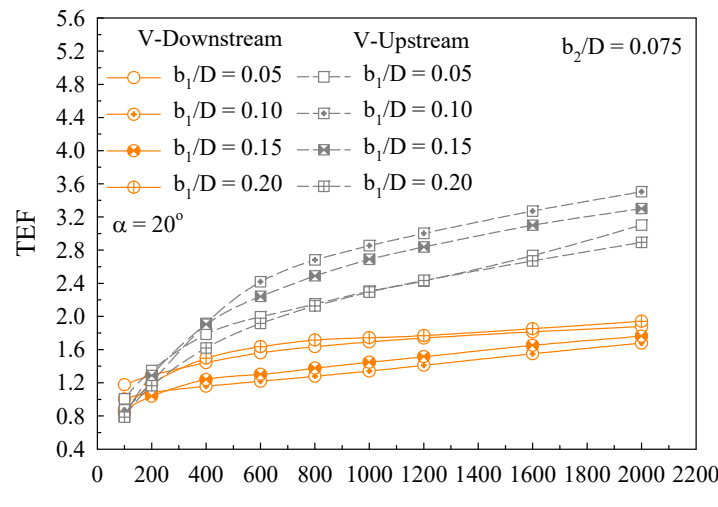

Re

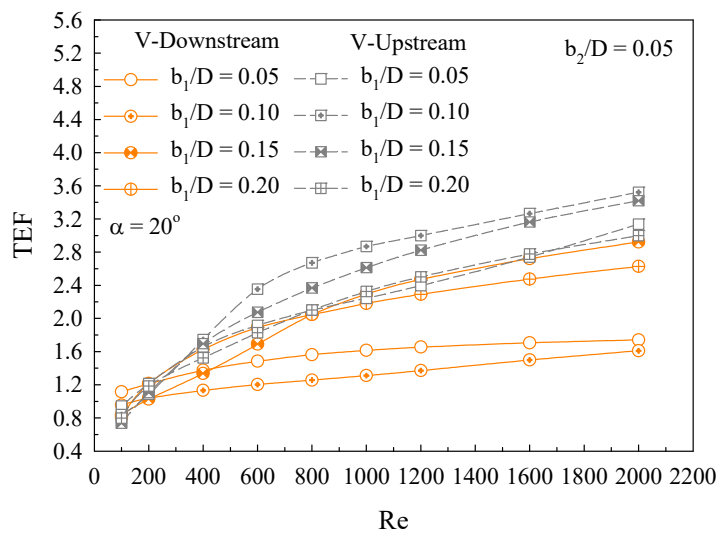

(b)

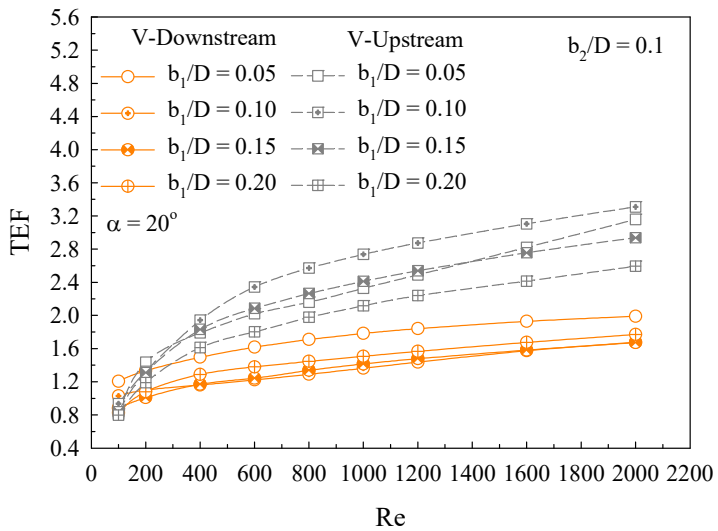

(d)

Fig. 23 TEF vs Re of $\alpha=20^{\circ}$ for (a) $b_{2} / D=0.025$, (b) $b_{2} / D=0.05$, (c) $b_{2} / D=0.075$ and (d) $b_{2} / D=0.1$.

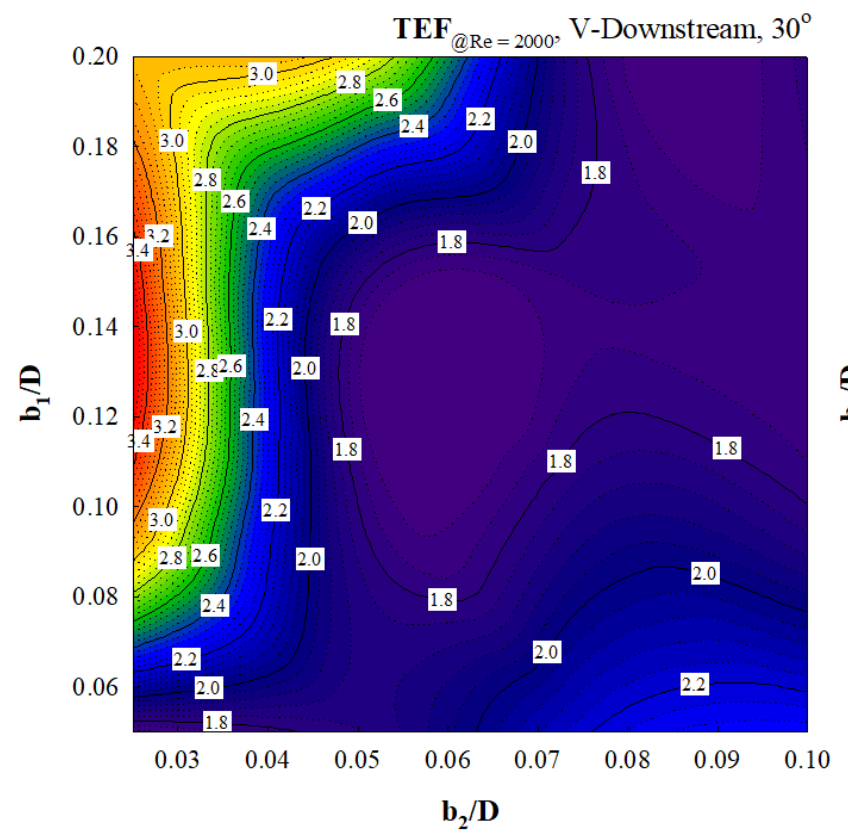

(a)

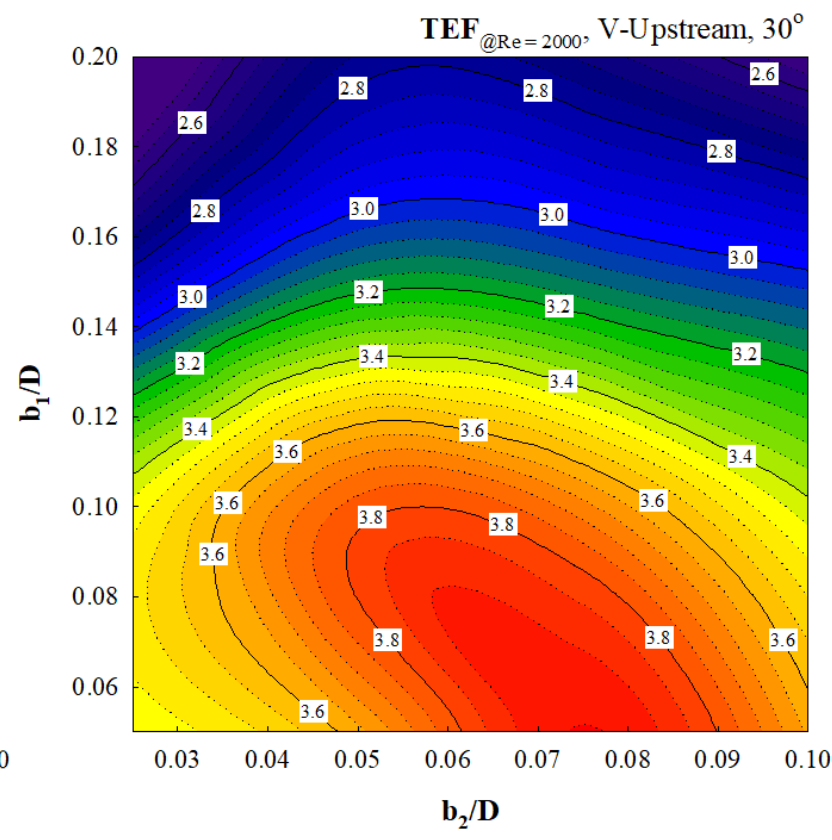

(b)

Fig. 24 TEF contours at $\operatorname{Re}=2000$ and $\alpha=30^{\circ}$ with various $b_{1} / D$ and $b_{2} / D$ values for (a) V-Downstream and (b) V-Upstream. 


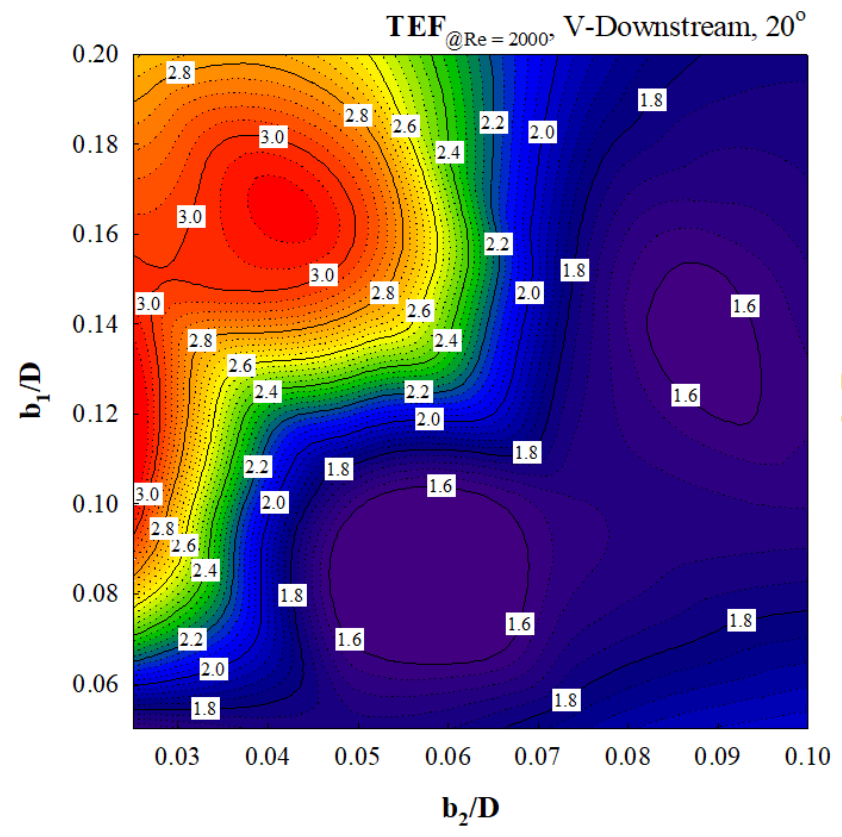

(a)

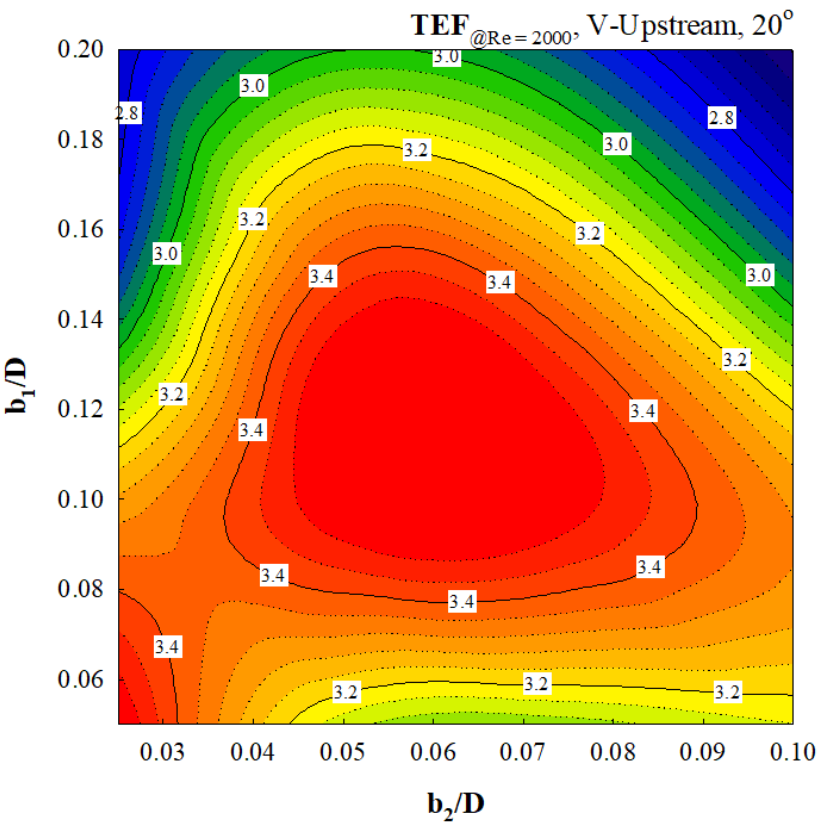

(b)

Fig. 25 TEF contours at $R e=2000$ and $\alpha=20^{\circ}$ with various $b_{1} / D$ and $b_{2} / D$ values for (a) V-Downstream and (b) V-Upstream.

\section{NUMERICAL VALIDATION}

It is very important to assure that the numerical model of the tested section gives high accuracy results. Therefore, the numerical model of the present investigation is validated. The validations of the numerical model can be split into two parts: 1. smooth tube validation and 2. grid independence or grid test. For the smooth tube validation, the comparisons between the values from the correlations (Cengel and Ghajar (2015)) both Nusselt number and friction factor and the values from the present model are plotted as Fig. 2. The correlations of the Nusselt number and friction factor for the smooth circular tube are written as equations 10 and 11 , respectively.

$\mathrm{Nu}=3.66$

$f=64 / \mathrm{Re}$

As the figure, it is noticed that the deviations of the Nusselt number and friction factor are not higher than $\pm 10 \%$. The four different models with various grid cells are compared as Figs. 3a and b, respectively, for the Nusselt number ratio and friction factor ratio. The increased grid element from 220000 to 360000 has no impact on fluid flow and heat transfer characteristics. Therefore, the numerical model with the grid cell of 220000 is selected for the current study. As the numerical data in this section, it can be concluded that the numerical model of the CTMVB can predict the flow and heat transfer profiles with high precision results.

\section{NUMERICAL RESULT}

\subsection{Heat transfer and flow structure}

Figs. $4 \mathrm{a}$ and $\mathrm{b}$ plot the streamlines in transverse planes for the CTMVB at $b_{1} / D=0.15, b_{2} / D=0.05, R e=800$ and $\alpha=30^{\circ}$ for V-Downstream and V-Upstream directions, respectively. As the figures, the MVB produces the vortex flows through the tested tube for both directions. There are eight vortex cores in each plane. The two pairs of the vortex flows $\left(\mathrm{V}_{1}\right)$, which are formed by the baffle near the wall, are detected at the upper and lower regimes of the plane. The other two pairs of the vortex flows $\left(\mathrm{V}_{2}\right)$, which are produced by the baffle at the core of the round tube, are found at the middle regime of the plane (See Fig. 5). The vortex flows $\left(\mathrm{V}_{1}\right)$ near the tube wall interrupt thermal boundary layer on the heat transfer surface. The vortex flows $\left(\mathrm{V}_{2}\right)$ at the core of the round tube can help to improve air blending. These phenomena are significant causes for the improvement of the heat transfer coefficient in the round tube. The different rotation of the vortex flows is found when changing flow direction of the MVB (See Fig. 6). The different flow behavior influences for the differentiation of the heat transfer mechanism. The flow configuration in the tested section slightly changes when changing baffle height.

The longitudinal flows in the tested section equipped with $\mathrm{V}$ Downstream and V-Upstream directions of the MVB are plotted as Figs. 7a and $b$, respectively. The impinging streams on the tube wall are detected for both arrangements. The impingements on the left and right regimes of the round tube are found for the V-Downstream arrangement, while found at the upper-lower parts of the round tube for the V-Upstream case. The impinging flow disturbs thermal boundary layer. The disturbed thermal boundary layer is an important reason for the heat transfer augmentation.

The pressure contours in transverse planes of the CYMVB are presents in Figs. 8a and $\mathrm{b}$ for V-Downstream and V-Upstream, respectively. As the figures, the different pressure between in front of the MVB and behind the MVB is clearly found for both flow directions. The different pressure is a cause for the generation of the vortex flows. The pressure loss across the MVB augments when increasing the MVB height.

Figs. 9a and $\mathrm{b}$ report the temperature distributions in $\mathrm{y}-\mathrm{z}$ planes for the CTMVB with V-tips directing Downstream and Upstream, respectively, at similar conditions. As the figures, the greater fluid mixing is obviously found for both cases. The changes of the thermal boundary layer are not in similar pattern when varying flow directions. The red layer near the tube wall is a guide to discuss the variation of the thermal boundary layer in the round tube. The red layer thickness reduces when the thermal boundary layer is disturbed. The thermal boundary layer disturbance in the V-Upstream cases is obviously detected for whole wall, while is observed only at the left and right sections of the plane for the V-Downstream arrangement. The MVB with V-Upstream arrangement generates the vortex flows, which disturb all regimes of the tube, while the vortex flows which are created by the V-Downstream arrangement disturb only left and right parts of 
the tube wall. This means that the V-Upstream case may bring better heat transfer rate than the V-Downstream case.

The flow and heat transfer patterns in the tube at $b_{2} / D=0.075$ with various $b_{1} / D$ values are portrayed as Figs. 10 and 11, respectively, for $\mathrm{V}$-Downstream and V-Upstream directions. The vortex flows $\left(\mathrm{V}_{1}\right)$, which is created by the baffle near the tube wall, expand, while the vortex flows $\left(\mathrm{V}_{2}\right)$, which are produced by the baffle at the center of the tube, reduce when increasing $b_{1} / D$ for both arrangements. The extended vortex flow $\left(\mathrm{V}_{1}\right)$ is due to the increment of the baffle height, while the reduced vortex flow $\left(\mathrm{V}_{2}\right)$ is due to the oppression by the other vortex flow. The vortex size directly affects for the vortex strength and disturbed thermal boundary layer. The optimum baffle size may give the highest heat transfer rate and thermal performance.

The heat transfer and flow profiles in the heat exchanger tube for $b_{1} / D=0.15$ with various $b_{2} / D$ values are plotted as Figs. 12 and 13 for V-Downstream and V-Upstream cases, respectively. For the VDownstream case, the vortex flows $\left(\mathrm{V}_{2}\right)$ at the center of the tested section extend when augmenting $b_{2} / D$. The extended vortex flow $\left(V_{2}\right)$ encroaches the vortex flow $\left(\mathrm{V}_{1}\right)$ near the tube wall. The most thermal boundary layer disturbance is obviously detected at $\mathrm{b}_{2} / \mathrm{D}=0.025$.

For the V-Upstream direction, the vortex flows $\left(\mathrm{V}_{2}\right)$ at the center of the tested section gently grow up when augmenting $\mathrm{b}_{2} / \mathrm{D}$. The heat transfer profiles (red layer thickness) in the tested section with various $b_{2} / D$ values are found to be slightly difference. This means that the vortex flows $\left(\mathrm{V}_{1}\right)$ near the tube wall have higher strength than the vortex flows $\left(\mathrm{V}_{2}\right)$ at the center of the tube. The vortex flows $\left(\mathrm{V}_{1}\right)$ near the tube wall interrupts the development of the vortex flows $\left(\mathrm{V}_{2}\right)$ at the center of the tested tube.

Figs. 14 and 15 plot the local Nusselt number contours on the tube wall of the CTMVB for V-Downstream and V-Upstream arrangements, respectively, at $b_{2} / D=0.075$ with various $b_{1} / D$ values. For the $V$ Downstream, the decreased Nusselt number at the upper-lower parts with the increased Nusselt number at the left-right parts are observed when augmenting $b_{1} / D$ value. This is because the impinging flows at the left-right parts are more powerful than the impinging flows at the upper-lower regimes.

For the V-Upstream arrangement, the decreased Nusselt number at the left-right sections with the enhanced Nusselt number at the upperlower zones of the tube are seen when increasing $b_{1} / D$ value. The impinging flows on the heat transfer surface at the upper-lower parts of the tube are stronger than the impinging flows at the left-right sections when increasing $b_{1} / D$.

The variations of the local Nusselt number at various $b_{2} / D$ for $b_{1} / D$ $=0.15$ are illustrated as Figs. 16 and 17, respectively, for VDownstream and V-Upstream arrangements. For the V-Downstream case in a range $0.025 \leq b_{2} / D \leq 0.05$, the Nusselt number at the left-right parts decreases when augmenting $b_{2} / D$.

For the V-Upstream direction, the Nusselt number at the left-right parts of the tube slightly augments when enhancing $b_{2} / D$. The local Nusselt number at the upper-lower parts is observed to be nearly constant when increasing the $\mathrm{b}_{2} / \mathrm{D}$. The heat transfer and flow forms in the CTMVB for the baffle angles of $20^{\circ}$ and $30^{\circ}$ are similarly found. This is because the flow and heat transfer profiles in the tested tube depend on vortex generator type. The changes of the vortex generator parameters such as height and flow attack angle, affect only for the changes of vortex strength and vortex core position.

\subsection{Thermal performance assessment}

The relations of the Nusselt number ratio, $\mathrm{Nu} / \mathrm{Nu}_{0}$, with the Reynolds number for the CTMVB are plotted as Figs. 18 and 19 for $\alpha=30^{\circ}$ and $20^{\circ}$, respectively, at various $b_{1} / D, b_{2} / D$, Reynolds numbers and flow directions. The heat transfer coefficient in the tested section increases when rising Reynolds number and $b_{1} / D$ due to the growth of the vortex strength. The vortex strength directly affects for the thermal boundary layer disturbance. The heat transfer rate in the CTMVB is about $1.18-$ $12.33,1.32-12.96,1.44-8.25$ and $1.60-9.76$ times above the smooth round tube for $\mathrm{b}_{2} / \mathrm{D}=0.025,0.05,0.075$ and 0.1 , respectively, for $\mathrm{V}$ -
Downstream arrangement at $\alpha=30^{\circ}$. For V-Upstream case and $\alpha=30^{\circ}$, the Nusselt number is found to be about $1.04-9.44,1.19-12.58,1.39$ -14.15 and $1.58-15.16$ times greater the general tube for $b_{2} / D=$ $0.025,0.05,0.075$ and 0.1 , respectively. The baffle angle of $20^{\circ}$ gives the $\mathrm{Nu} / \mathrm{Nu}_{0}$ around $1.16-8.03,1.26-8.11,1.42-6.61$ and $1.54-6.96$ for $\mathrm{b}_{2} / \mathrm{D}=0.025,0.05,0.075$ and 0.1 , respectively, of V-Downstream, while around $1.02-8.26,1.11-9.86,1.29-10.74$ and $1.21-10.87$ for V-Upstream, respectively.

Figs. 20 and 21 present the relations of the friction factor ratio, $\mathrm{f} / \mathrm{f}_{0}$, with the Reynolds number at different $b_{1} / D, b_{2} / D$, flow directions and Reynolds numbers in the CTMVB for $\alpha=30^{\circ}$ and $20^{\circ}$, respectively. The friction factor in the CTMVB significantly increases when enhancing Reynolds number and blockage ratio. The baffle angle of $20^{\circ}$ performs lower friction loss than the angle of $30^{\circ}$. The highest friction loss is found at the highest blockage ratio for the flow attack angle of $30^{\circ}$ of about 165.3 and 218.07 for V-Downstream and V-Upstream arrangements, respectively.

The relations of the thermal enhancement factor with the Reynolds number in the CTMVB are shown as Figs. 22 and 23, respectively, for $\alpha=30^{\circ}$ and $20^{\circ}$. The maximum TEF of about 3.92 is found at $b_{1} / D=$ $0.05, \mathrm{~b}_{2} / \mathrm{D}=0.075, \alpha=30^{\circ}, \mathrm{V}$-Upstream direction at $\mathrm{Re}=2000$.

In comparison, the V-Upstream arrangement brings higher thermal performance that the V-Downstream arrangement (as Fig. 24 and 25). This is because the V-Upstream gives the optimum longitudinal vortex pitch for the disturbance of the thermal boundary layer.

\section{CONCLUSION}

Numerical assessments on flow and heat transfer patterns in the CTMVB at various MVB heights, angle of attacks, Reynolds numbers and flow directions are presented. The main findings for this research can be concluded as follows.

The addition of the MVB in the round tube provides better heat transfer rate than the smooth tube due to the disturbed thermal boundary layer and superior fluid mixing.

The vortex flows in the CTMVB can be separated into two sections: vortex flows at the middle of the tested section and vortex flows near the tube wall. The vortex flows at the middle of the tested section help about the fluid mixing, while the vortex flows near the tube wall disturb thermal boundary layer. These mechanisms are important reasons for heat transfer and thermal performance developments. In the range investigation, the TEF is found to be around $0.80-3.92$ based on $\mathrm{b}_{1} / \mathrm{D}, \mathrm{b}_{2} / \mathrm{D}, \alpha$, flow direction and $\mathrm{Re}$.

In comparison, the present vortex generator gives the maximum thermal performance higher than the V- baffles which are located on the tube wall (Jedsadaratanachai et al. (2015)). The installation and maintenance of the present vortex generator are more convenient when compared with the V-baffles which are placed on the tube wall.

\section{ACKNOWLEDGMENTS}

The authors would like to acknowledge Assoc. Prof. Dr. Pongjet Promvonge for suggestions. This research was funded by College of Industrial Technology, King Mongkut's University of Technology North Bangkok (Grant No. Res-CIT0284/2021).

\section{SYMBOL}

$b_{1} \quad$ baffle (on the tube wall) height, $m$

$\mathrm{b}_{2} \quad$ baffle (at the middle of the tube) height, $\mathrm{m}$

D tube diameter, $m$

f friction factor

h convective heat transfer coefficient, $\mathrm{W} \mathrm{m}^{-2} \mathrm{~K}^{-1}$

$\mathrm{k}$ thermal conductivity, $\mathrm{W} \mathrm{m}^{-1} \mathrm{~K}^{-1}$

$\mathrm{L}$ periodic length of the physical model, $\mathrm{m}$

$\mathrm{Nu} \quad$ Nusselt number $(=\mathrm{hD} / \mathrm{k})$

$\mathrm{P} \quad$ pitch distance, $\mathrm{m}$

$\mathrm{p} \quad$ static pressure, $\mathrm{Pa}$

Re Reynolds number 
$\mathrm{T} \quad$ temperature, $\mathrm{K}$

$\bar{u} \quad$ mean velocity in channel, $\mathrm{m} \mathrm{s}^{-1}$

\section{Greek letter}

$\begin{array}{ll}\rho & \text { density, } \mathrm{kg} \mathrm{m}^{-3} \\ \mu & \text { dynamic viscosity, } \mathrm{kg} \mathrm{m}^{-1} \mathrm{~s}^{-1}\end{array}$

Subscript

$0 \quad$ plain duct

pp pumping power

Abbreviation

CTMVB Circular tube inserted with modified V-baffle

MVB Modified V-baffle

TEF Thermal Efficiency Factor $\left(=\left(\mathrm{Nu} / \mathrm{Nu}_{0}\right) /\left(\mathrm{f} / \mathrm{f}_{0}\right)^{1 / 3}\right)$

\section{REFERENCE}

Abotsi, O.Y.W., and Kizito, J., 2020, "Turbulent Heat Transfer in an Axially Rotating Pipe at High Rotation Rate: A Numerical Study", Frontiers in Heat and Mass Transfer, 14 - 24.

http://dx.doi.org/10.5098/hmt.14.24

Bahiraei, M., Monavari, A., and Moayedi, H., 2020, "Second Law Assessment of Nanofluid Flow in a Channel Fitted with Conical Ribs for Utilization in Solar Thermal Applications: Effect of Nanoparticle Shape", International Journal of Heat and Mass Transfer, 151, Article 119387.

https://doi.org/10.1016/j.ijheatmasstransfer.2020.119387

Bahiraei, M., Mazaheri, N., and Moayedi, H., 2020, "Employing Vshaped Ribs and Nanofluid as Two Passive Methods to Improve Second Law Characteristics of Flow within a Square Channel: A Two-phase Approach", International Journal of Heat and Mass Transfer, 151, Article 119419.

https://doi.org/10.1016/i.ijheatmasstransfer.2020.119419

Bahiraei, M., Mazaheri, N., Hosseini, Y., and Moayedi, H., 2019, “A Two-phase Simulation for Analyzing Thermohydraulic Performance of $\mathrm{Cu}$-water Nanofluid within a Square Channel Enhanced with $90^{\circ} \mathrm{V}$ shaped Ribs", International Journal of Heat and Mass Transfer, 145, Article 118612.

https://doi.org/10.1016/j.ijheatmasstransfer.2019.118612

Bai, W., Chen, W., Yang, L., and Chyu, M.K., 2019, "Numerical Investigation on Heat Transfer and Pressure Drop of Pin-fin Array Under the Influence of Rib Turbulators Induced Vortices", International Journal of Heat and Mass Transfer, 129, 735-745. https://doi.org/10.1016/j.ijheatmasstransfer.2018.10.022

Bai, W., Liang, D., Chen, W., and Chyu, M.K., 2019, "Investigation of Ribs Disturbed Entrance Effect of Heat Transfer and Pressure Drop in Pin-fin Array", Applied Thermal Engineering, 162, Article 114214. https://doi.org/10.1016/j.applthermaleng.2019.114214

Boonloi, A., and Jedsadaratanachai, W., 2018a, "Effect of Flow Attack Angle for V-Wavy Plate on Flow and Heat Transfer in a Square Channel Heat Exchanger", Journal of Engineering, 2018, Article ID 9487070.

https://doi.org/10.1155/2018/9487070

Boonloi, A., and Jedsadaratanachai, W., 2018b, "Effect of Location in Transverse Plane for 45-degree V-baffle on Flow and Heat Transfer Mechanisms in a Square Channel", Frontiers in Heat and Mass Transfer, 11 - 29. https://doi.org/10.5098/hmt.11.29

Boonloi, A., and Jedsadaratanachai, W., 2019a, "Numerical Study on Flow and Heat Transfer Mechanisms in the Heat Exchanger Channel with V-orifice at Various Blockage Ratios, Gap Spacing Ratios, and Flow Directions", Modelling and Simulation in Engineering, 2019, Article ID 8656435.

https://doi.org/10.1155/2019/8656435

Boonloi, A., and Jedsadaratanachai, W., 2019b, "Thermal Performance Improvement in a Square Channel Heat Exchanger with Various Parameters of V-wavy Plates", Frontiers in Heat and Mass Transfer, 12 - 1.

https://doi.org/10.5098/hmt.12.1

Boonloi, A., and Jedsadaratanachai, W., 2014, "Thermal Performance Analysis and Empirical Correlations for Laminar Forced Convection over $30^{\circ}$ V-baffled Square Channel", Advances in Mechanical Engineering, 2014, Article ID 930272.

https://doi.org/10.1155/2014/930272

Cengel, Y.A., and Ghajar, A.J., 2015, "Heat and Mass Transfer: Fundamentals \& applications", Fifth edition in SI Units, McGraw-Hill Education, ISBN 978-981-4595-27-8.

Chamoli, S., Lu, R., Xie, J., and Yu, P., 2018a, "Numerical Study on Flow Structure and Heat Transfer in a Circular Tube Integrated with Novel Anchor Shaped Inserts", Applied Thermal Engineering, 135, 304-324.

https://doi.org/10.1016/j.applthermaleng.2018.02.052.

Chamoli, S., Lu, R., Xu, D., and Yu, P., 2018b, "Thermal Performance Improvement of a Solar Air Heater Fitted with Winglet Vortex Generators", Solar Energy, 159, 966-983.

https://doi.org/10.1016/j.solener.2017.11.046.

Eiamsa-ard, S., Ruengpayungsak, K., Thianpong, C., Pimsarn, M., and Chuwattanakul, V., 2019, "Parametric Study on Thermal Enhancement and Flow Characteristics in a Heat Exchanger Tube Installed with Protruded Baffle Bundles", International Journal of Thermal Sciences, 145, Article 106016.

https://doi.org/10.1016/j.ijthermalsci.2019.106016."

Gao, Q., Zhang, K., and Wang, L.B., 2020, "Numerical Analysis of Natural Convection in Internally Finned Horizontal Annuli", Frontiers in Heat and Mass Transfer, 14 - 29.

http://dx.doi.org/10.5098/hmt.14.29

Gu, X., Jiang, G., Wo, Y., and Chen, B., 2020, "Numerical Study on Heat Transfer Characteristics of Propylene Glycol-water Mixture in Shell Side of Spiral Wound Heat Exchanger", Frontiers in Heat and Mass Transfer, 15 - 3.

http://dx.doi.org/10.5098/hmt.15.3

Gupta, A., Roy, A., Gupta, S., and Gupta, M., 2020, "Numerical Investigation Towards Implementation of Punched Winglet as Vortex Generator for Performance Improvement of a Fin-and-tube Heat Exchanger", International Journal of Heat and Mass Transfer, 149, Article 119171. 
https://doi.org/10.1016/j.ijheatmasstransfer.2019.119171

Hiratsuka, W., Fukue, T., Shirakawa, H., Nakayama, K., and Koito, Y., 2020, "CFD-Based Study on Heat Transfer Enhancement Behind a Projection in a Miniaturized Flow Channel by Pulsating Flow", Frontiers in Heat and Mass Transfer, 15 - 16.

http://dx.doi.org/10.5098/hmt.15.16

Jedsadaratanachai, W., and Boonloi, A., 2017, "Performance Analysis and Flow Visualization in a Round Tube Heat Exchanger Inserted with Wavy V-ribs", Advances in Mechanical Engineering, 9, 1-16. https://doi.org/10.1177/1687814017724091

Jedsadaratanachai, W., Jayranaiwachira, N., and Promvonge, P., 2015, "3D Numerical Study on Flow Structure and Heat Transfer in a Circular Tube with V-baffles", Chinese Journal of Chemical Engineering, 23, 342-349.

https://doi.org/10.1016/j.cjche.2014.11.006

Jiang, G., Gao, J., Shi, X., Li, F., and Xu, L., 2020, "Flow and Heat Transfer Characteristics of the Mist/steam Two-phase Flow Cooling the Rectangular Channel with Column-row-ribs", International Journal of Heat and Mass Transfer, 156, Article 119737.

https://doi.org/10.1016/j.ijheatmasstransfer.2020.119737

Jinlong, X., and Hsiao Mun, L., 2020, "Flow and Heat Transfer Performances of Directly Printed Curved-rectangular Vortex Generators in a Compact Fin-tube Heat exchanger", Applied Thermal Engineering, 180, Article 115830.

https://doi.org/10.1016/j.applthermaleng.2020.115830

Khoshvaght-Aliabadi, M., Khoshvaght, M., and Rahnama, P., 2016, "Thermal-hydraulic Characteristics of Plate-fin Heat Exchangers with Corrugated/vortex-generator Plate-fin (CVGPF)", Applied Thermal Engineering, 98, 690-701.

https://doi.org/10.1016/j.applthermaleng.2015.12.135

Li, F., Ma, Q., Xin, G., Zhang, J., and Wang, X., 2020, "Heat Transfer and Flow Characteristics of Microchannels with Solid and Porous Ribs", Applied Thermal Engineering, 178, Article 115639. https://doi.org/10.1016/j.applthermaleng.2020.115639

Li, P., Xu, C., Liao, Z., Ju, X., and Ye, F., 2020, "Numerical Investigation on the Thermal Performance of a Cascaded Latent Heat Thermal Energy Storage", Frontiers in Heat and Mass Transfer, 15 10.

http://dx.doi.org/10.5098/hmt.15.10

Li, Y., Rao, Y., Wang, D., Zhang, P., and Wu, X., 2019, "Heat Transfer and Pressure Loss of Turbulent Flow in Channels with Miniature
Structured Ribs on One Wall", International Journal of Heat and Mass Transfer, 131, 584-593.

https://doi.org/10.1016/j.ijheatmasstransfer.2018.11.067

Liu, P., Zheng, N., Shan, F., Liu, Z., and Liu, W., 2018, "An Experimental and Numerical Study on the Laminar Heat Transfer and Flow Characteristics of a Circular Tube Fitted with Multiple Conical Strips Inserts", International Journal of Heat and Mass Transfer, 117, 691-709.

https://doi.org/10.1016/j.ijheatmasstransfer.2017.10.035.

Luan, N.T. and Phu, N.M., 2020, "Thermohydraulic Correlations and Exergy Analysis of a Solar Air Heater Duct with Inclined Baffles", Case Studies in Thermal Engineering, 21, Article 100672.

https://doi.org/10.1016/j.csite.2020.100672

Matsubara, K., Ohta, H., and Ishino, T., 2020, "Direct Simulation of Inlet Region Heat Transfer in a Channel with Repeated Ribs Under Isothermal Wall Heating Condition", International Journal of Thermal Sciences, 154, Article 106408.

https://doi.org/10.1016/j.ijthermalsci.2020.106408

Modi, A.J., Kalel, N.A., and Rathod, M.K., 2020, "Thermal Performance Augmentation of Fin-and-tube Heat Exchanger Using Rectangular Winglet Vortex Generators Having Circular Punched Holes", International Journal of Heat and Mass Transfer, 158, Article 119724.

https://doi.org/10.1016/j.ijheatmasstransfer.2020.119724

Phila, A., Eiamsa-ard, S. and Thianpong, C., 2020, "Thermal Performance Evaluation of a Channel Installed with Inclined-Baffle Turbulators", Arabian Journal for Science and Engineering, 45, 609621.

https://doi.org/10.1007/s13369-019-04097-x

Piriyarungrod, N., Kumar, M., Thianpong, C., Pimsarn, M., Chuwattanakul, V., and Eiamsa-ard, S., 2018, "Intensification of Thermo-hydraulic Performance in Heat Exchanger Tube Inserted with Multiple Twisted-tapes", Applied Thermal Engineering, 136, 516-530. https://doi.org/10.1016/j.applthermaleng.2018.02.097.

Samadifar, M., and Toghraie, D., 2018, "Numerical Simulation of Heat Transfer Enhancement in a Plate-fin Heat Exchanger Using a New Type of Vortex Generators", Applied Thermal Engineering, 133, 671681.

https://doi.org/10.1016/j.applthermaleng.2018.01.062

Yu, C., Zhang, H., Zeng, M., Wang, R., and Gao, B., 2020, "Numerical Study on Turbulent Heat Transfer Performance of a New Compound Parallel Flow Shell and Tube Heat Exchanger with Longitudinal Vortex Generator", Applied Thermal Engineering, 164, Article 114449. https://doi.org/10.1016/j.applthermaleng.2019.114449 